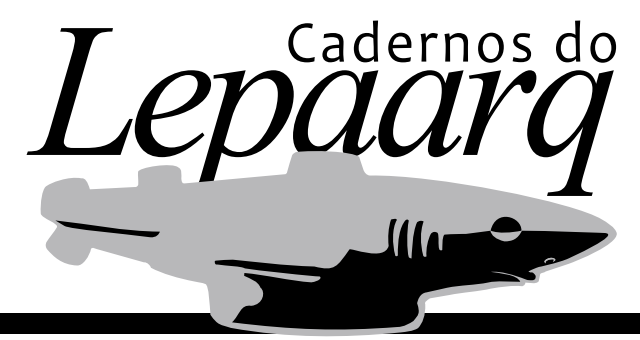

\title{
PROCESSOS E MODELOS: A ARQUEOLOGIA DE COLIN RENFREW
}

Giovanna Ceserani

Tradução: Renan Falcheti Peixoto

Como citar este artigo:

CESERANI, Giovanna. Processos e modelos: a arqueologia de Colin Renfrew. Cadernos do Lepaarq, v. XVII, n.34, p. 345-391, Jul-Dez. 2020. 


\title{
Processos e modelos: a arqueologia de Colin Renfrew ${ }^{\mathrm{a}}$
}

\author{
Giovanna Ceserani ${ }^{\mathrm{b}}$ \\ Tradução: Renan Falcheti Peixoto ${ }^{c}$
}

\section{Resumo:}

O tema da "mudança do processo cultural" tem uma presença constante na pesquisa de Colin Renfrew, nas várias áreas de interesse nos quais ele está articulado, da pré-história do Egeu à pré-história britânica, dos trabalhos dedicados à teoria e à metodologia da arqueologia até as contribuições sobre a questão das línguas indo-europeias. Meu objetivo é procurar compreender como esse tema foi desenvolvido, de quais influências foi nutrido, quais resultados produziu, as razões de sua centralidade e, enfim, como ele determinou a identidade do estudioso Renfrew.

\begin{abstract}
:
The theme of "process of culture change" has a constant presence in Colin Renfrew's research, in the various areas of interest in which it is articulated, from Aegean prehistory to British prehistory, from works devoted to theory and methodology of archeology to contributions on the issue of Indo-European languages. My aim here is to understand how this theme was developed, what influences it was nurtured, what results it produced, the reasons for its centrality and, finally, how it determined the identity of the scholar Renfrew.
\end{abstract}

\section{Palavras-chave:}

Renfrew; mudança cultural; teoria arqueológica.

\section{Keywords:}

Renfrew; cultural change; archaeological theory.

\footnotetext{
${ }^{a}$ O presente texto foi publicado originalmente sob o título Processi e modelli: l'archeologia di Colin Renfrew no periódico Annali della Scuola Normale Superiore di Pisa. Classe di Lettere e Filosofia, v. IV, n. 2, p. 363-410, 1997.

${ }^{\mathrm{b}}$ Professora Associada de Clássicos na Universidade de Stanford. Sua pesquisa concentra-se na tradição clássica, com ênfase na história intelectual da erudição clássica, historiografia e arqueologia do século XVIII em diante. Ela é também autora do livro Italy’s Lost Greece: Magna Graecia and the Making of Modern Archaeology (Oxford University Press, 2012).

${ }^{\mathrm{c}}$ Duplo doutoramento em andamento no Museu de Arqueologia e Etnologia da Universidade de São Paulo (MAE-USP) e no Dipartimento di Storia Culture Civiltà (DiSCi) da Alma Mater Studiorum - Università di Bologna (UNIBO), com bolsas de estudos da Fundação de Amparo à Pesquisa do Estado de São Paulo (FAPESP - Bolsa DR 18/06265-0 e Bolsa BEPE 19/24957-9). Mestre em Arqueologia pelo MAE-USP (2017), com financiamento de pesquisa da FAPESP. Licenciado e Bacharel em História pela Universidade Estadual Paulista "Júlio de Mesquita Filho", Faculdade de Ciências Humanas e Sociais de Franca (UNESP-FCHS-2012). falcheti.peixoto@usp.br
} 


\section{INTRODUÇÃO}

O tema da "mudança do processo cultural" tem uma presença constante na pesquisa de Colin Renfrew, nas várias áreas de interesse nos quais ele está articulado, da pré-história do Egeu à pré-história britânica, dos trabalhos dedicados à teoria e à metodologia da arqueologia até as contribuições sobre a questão das línguas indo-europeias. Meu objetivo é procurar compreender como esse tema foi desenvolvido, de quais influências foi nutrido, quais resultados produziu, as razões de sua centralidade e, enfim, como ele determinou a identidade do estudioso Renfrew.

A contribuição mais relevante de Renfrew para a reflexão sobre a mudança cultural está constituída pela elaboração de uma abordagem da investigação arqueológica por meio de modelos. Essa proposta metodológica foi definida através de uma série de tentativas, que podem ser vistas seja como momentos de tempos em tempos autônomos da pesquisa, seja retrospectivamente como progressiva aproximação em direção a uma proposta mais complexa. O que caracteriza os modelos dos quais fala Renfrew, mesmo na mudança de suas formulações, é o fato deles não serem aplicáveis diretamente aos dados arqueológicos, mas às realidades sociais conjecturadas no princípio da recuperação arqueológica dos restos materiais.

Entre os anos sessenta e setenta, os modelos estavam no centro dos debates mais inovadores tanto em história antiga ${ }^{1}$, quanto em arqueologia, onde se destacam por vivaz polêmica disruptiva as discussões desenvolvidas no seio da New Archaeology [Nova Arqueologia] estadunidense (ou arqueologia processual) ${ }^{2}$. De acordo com a primeira geração da Nova Arqueologia, uma explicação somente é válida se formulada sobre a forma de leis; a investigação de tais leis representa o propósito último da arqueologia ${ }^{3}$. A posição de Renfrew é, de princípio, mais nebulosa: ele aspira mais a identificar o valor das explicações com a possibilidade de suas generalizações. A abordagem sistêmica para o estudo da cultura e conceito de processo cultural são outros aspectos da pesquisa de Renfrew ligados à Nova Arqueologia; a arqueologia social dos modelos, ao invés, é uma elaboração original sua, a sua rota de saída da compactação da escola do grupo da Nova Arqueologia quando esta veio a diferenciar-se. Permanecem todavia alguns nós problemáticos relacionados aos modelos de Renfrew e sua natureza incerta entre leis e generalizações. Como se formam os modelos, quando esses são a priori e quando a posteriori, qual é a relação deles com os dados empíricos? Com base em quais critérios e qual concepção de cultura eles podem ser generalizados e usados em contextos culturais diversos? Ao longo dos anos, embora Renfrew mude a concepção e o tipo de modelos utilizados, não aprofunda os problemas postos por essas perguntas; em uma obra que se apresenta imponente por amplitude e complexidade, estruturais talvez sejam esses pontos criticáveis.

Uma outra tendência dominante nos anos sessenta marca o trabalho de Renfrew e da Nova

\footnotetext{
$1 \quad$ Veja as discussões que faz referência Moses Finley (1985).

2 Um exame crítico do percurso de Renfrew representa também uma contribuição à discussão sobre a Nova Arqueologia, não está entre os propósitos desse artigo tratar em sua complexidade esse problema historiográfico, ao qual acenarei quando examinar o momento no qual Renfrew entrou em contato com os novos arqueólogos [new archaeologists] estadunidenses.
}

$3 \quad$ Veja BINFORD; BINFORD, 1968. 
Arqueologia: a atenção para as ciências naturais, tanto pelas novas técnicas aplicáveis à arqueologia quanto às estruturas teóricas das disciplinas científicas sobre as quais a arqueologia procura modelar os próprios métodos de investigação após a chamada "perda da inocência". Na obra de Renfrew, as ciências naturais tem papel forte e característico. Das novas técnicas dependem muitos de seus resultados. Com base no modo de proceder das ciências naturais ele deseja informar o método de seu trabalho: a concepção dos modelos é fortemente influenciada pelas ciências. De tudo isso resulta também um forte componente de interdisciplinaridade. Talvez sua concepção de ciência seja 'à velha maneira': os dados são apresentados como não problemáticos; à ampliação dos dados, em vez de um aprofundamento das perguntas, são confiadas as respostas.

É um percurso em contínuo desenvolvimento, assinalado também por contradições. Contraditório é o relacionamento com a arqueologia tradicional europeia. Renfrew se distinge de fato dentro da Nova Arqueologia por seu vínculo com a concepção histórica da pré-história, algo que sempre foi visto com simpatia por parte dos críticos da Nova Arqueologia, enquanto suscitou um certo senso de distanciamento dos novos arqueólogos puros. Esse aspecto da obra de Renfrew é parte de uma herança ambígua; ele conduz, mesmo no distanciamento declarado da tradição, também à conservação de algumas perguntas e de um modo de afrontá-las típico da tradição europeia: são exemplos claros a discussão sobre a origem dos indo-europeus e da identidade europeia na préhistória.

É no exame do percurso completo da obra de Renfrew que se coloca à luz o formar-se do principal tema de interesse das suas investigações, dos métodos para afrontá-lo e dos resultados obtidos, como também o desenvolvimento das ideias, das contradições, das reconsiderações e das reformulação de seu pensamento ${ }^{4}$.

\subsection{A formação de um arqueólogo do Egeu antigo}

Renfrew diplomou-se em arqueologia pela Universidade de Cambridge com 26 anos em 1962; em um primeiro momento ele havia se inscrito na faculdade de ciências naturais. A abordagem própria das ciências da natureza permaneceu uma constante tanto para a metodologia arqueológica como para o estabelecimento teórico de Renfrew. Em sua primeira resenha se lê: "as ciências naturais e a arqueologia estão progressivamente se aproximando e suas fronteiras coincidem em medida surpreendente. Esta relação tornou-se quase o fato mais importante na existência de um arqueólogo" (1964d, p. 153) ${ }^{5}$.

A forma científica permanecerá fundamental para a identidade de estudioso de Renfrew, uma vantagem não indiferente à compreensão das inovações científicas das quais se fará frequentemente tradutor para a comunidade dos arqueólogos.

\footnotetext{
$4 \quad$ Para um curriculum vitae de Renfrew veja RENFREW, 1993a, p. 51.

$5 \quad$ O livro de Leo Biek resenhado por Renfrew expõe as várias possíveis aplicações dos métodos científicos no estudo da arqueologia; a tradução, como outras não especificadas, é minha.
} 
Eleito Research Student [estudante de pós-graduação] do St. John's College, Renfrew prosseguiu os estudos escolhendo como argumento para a tese de doutorado $(P h D)$ as culturas pré-históricas das Cíclades: The Neolithic and Early Bronze Age Cultures of the Cyclades and their External Relations [As culturas do Neolítico e da Idade do Bronze Antigo das Cíclades e suas relações externas] (1965a), defendida em 1965. Na bibliografia aparece como "tese não publicada"; encontrase disponível para consulta na University Library de Cambridge.

Renfrew disse:

Durante aquele último ano eu escrevi para algumas pessoas e perguntei se esse seria um bom tema, e muitos deles disseram sim, essa era uma área importante. Nada de grande significância havia sido escrito desde o capítulo de Gordon Childe The Dawn of Civilisation [A aurora da civilização] em 1925, então esse era claramente algo que precisava ser olhado $(1973 b, \text { p. } 72)^{6}$.

Renfrew escolhia medir-se com o arqueólogo que, por todo o arco de sua atividade de estudioso, de 1926 a 1956, exerceu influência profunda sobre a arqueologia britânica, e não apenas britânica, desse século; apenas dez anos atrás Andrew Sherrat escreveu: "a pré-história é ainda hoje um diálogo com o fantasma de Childe" (SHERRATT, 1989, p. 185). Childe introduziu em arqueologia o conceito operativo de cultura como "conjunto recorrente de traços associados" (CHILDE, 1956, p. 133), acrescentando assim uma dimensão geográfica e de variação espacial àquela cronológica. A aplicação deste conceito permitiu-lhe produzir a primeira reconstrução cronológico-cultural compreensiva da pré-história europeia, orientada a um modelo difusionista, porém com uma atenção maior à complexidade e ductilidade desse instrumento. O fio condutor desta reconstrução é a difusão da civilização na Europa a partir do Próximo Oriente, onde se originou primeiro com a revolução agrícola e depois com a urbana, conceitos também elaborados por Childe. Nesse quadro, o Egeu desenvolve um papel importante: Creta é o primeiro lugar na Europa onde a agricultura foi introduzida e as aldeias tornaram-se cidades comerciais (CHILDE, 1925; trad. it. 1972, p. 26). Em vez disso, as Cíclades, desabitadas durante o Neolítico, tornaram-se um nó nevrálgico paras as civilizações urbanas subsequentes enquanto ricas em matéria-prima: seu acme cultural, a "civilização marítima" das Cíclades, é no III milênio a.C., quando constitui-se "uma ponte entre a Anatólia e a Grécia, uma via de comunicação para as ideias culturais entre a Ásia e a Europa" (CHILDE, 1925; trad. it. 1972, p. 57).

A obra de Childe forneceu as tramas históricas que os arqueólogos elaboraram nos anos sucessivos, dedicando-se à identificação das culturas arqueológicas segundo a definição programática de cultura, e à definição das relações entre elas com base nas semelhanças dos próprios artefatos.

A tese de doutorado de Renfrew insere-se nessa tradição: reordena e classifica o material cicládico com o objetivo de uma compreensão melhor do desenvolvimento do Neolítico e da Idade do Bronze nas Cíclades e, com isso, de uma base mais segura para as comparações com outras culturas mediterrânicas. Todavia, na introdução se evidencia claramente o desconforto do jovem

$6 \quad$ As traduções dos trechos citados de obras de Renfrew, exceto sua tese de doutoramento de acesso restrito, são baseadas nos textos originais em inglês, e não na tradução em italiano da autora (N. T.). 
estudioso em relação ao quadro histórico-cultural difusionista: "o que é necessário hoje, mais que uma pesquisa desse tipo, ou antes de novo material de escavação, é uma abordagem conceitual mais rigorosa e sistemática para a interpretação das evidências arqueológicas" (1965a, p. 7).

Renfrew critica o uso dos conceitos de "tipo", "cultura" e "período" e abandona a terminologia tradicional da Idade do Bronze: em vez de usar os termos Cicládico Antigo I, II e III, e as subdivisões em a, b e c, destinadas a criar confusão porque indicam ao mesmo tempo um tipo, uma cultura e um período, divide o material do Cicládico Antigo em três culturas sem preconceitos cronológicos. Depois, se demora sobre os conceitos de "invenção", "migração" e "difusão": sobre a base das classificações pouco claras do material das Cíclades, são identificadas semelhanças em cada parte do Mediterrâneo e teorizados contatos resultantes. Cético sobre a possibilidade destas comparações, mesmo diante de materiais bem classificados em grupos, ele mantém que um objetivo cada vez mais premente para a arqueologia seja a elaboração de uma "abordagem sistemática ao mecanismo da transmissão cultural” (1965a, p. 15).

O estudo do material cicládico representa uma contribuição notável ao conhecimento da pré-história do Egeu, uma virada em relação às poucas páginas reservadas às Cíclades por Childe em sua síntese da pré-história europeia. A aspiração explícita a uma alternativa ao difusionismo para explicar a mudança cultural não corresponde ainda à introdução de um novo modelo teórico. Uma primeira novidade está, contudo, no fato de que Renfrew identifica alguns assentamentos cicládicos remontantes ao Neolítico tardio. Trata-se de duas culturas diversas: a cultura Saliagos, do nome de uma ilhota próxima de Antiparos, onde Renfrew conduziu uma escavação com J.D. Evans (1968d), e a cultura de Kephala. A propósito da cultura de Kephala, o mais antigo cemitério escavado no Egeu, o discurso de Renfrew vai diretamente ao coração de importantes controvérsias: as mudanças nas práticas funerárias durante a pré-história são frequentemente usadas como prova de influências culturais e migrações da parte da escola difusionista. A existência agora demonstrada em Kephala de tumbas em pithos ${ }^{7}$ anteriores àquelas da Anatolia é uma prova contra o difusionismo e a "ex orient lux" de Childe.

Renfrew propõe uma cronologia relativa inovadora e convincente para a Idade do Bronze Antiga nas Cíclades, empreitada difícil porque o material do Cicládico Antigo, resultante das escavações do fim do século passado, era quase completamente privado de contexto e de estratigrafia. Childe havia dividido o material em dois grupos, uma meridional e um setentrional, Pelos e Syros, entre os quais não existia uma clara relação cronológica. Childe, além disso, na esteira de Åberg (1933), duvidada sobre a antiguidade de muitos dos materiais que eram atribuídos ao Médio ou até mesmo ao Bronze Tardio. Renfrew, em vez disso, através do estudo e a transcrição a máquina dos diários manuscritos de Mackenzie relativos à escavação de Phylakopi entre 1896-1898, conseguiu aclarar as dúvidas que sempre foram suscitadas sobre essa estratigrafia resultante das relações de escavação publicadas. No Cicládico Antigo ele identificava três culturas: a cultura Grota-Pelos (Neolítico finalinício Idade do Bronze Antigo II) que precede àquela de Keros-Syros (Idade do Bronze Antigo II),

$7 \quad$ Nome em grego para um receptáculo de grandes proporções feito de pasta cerâmica grosseira que em contextos funerários pode conter esqueletos inumados ou cinzas de cremações (N. T.). 
enquanto Phylakopi I é ainda mais tardia e se desenvolve até o Cicládico Médio.

Ao discutir as origens destas culturas, Renfrew dá muito relevo aos aspectos que indicam continuidade cronológica. Ele demonstra que as provas utilizadas para sustentar a derivação anatólia da cultura de Grotta-Pelos são de todo inconclusivas, e se declara a favor da ideia de um desenvolvimento paralelo nas duas regiões. A origem da cultura de Keros-Syros não é clara e Renfrew formula a hipótese propter necessitatem que uma fase anterior deveria ser trazida à luz, um nexo entre esta e a cultura neolítica de Kephala; aquela de Keros-Syros parece de fato continuar algumas de suas características. A propósito da cultura de Phylakopi I, Renfrew, contrariamente a quem a considera o resultado de influências externas, sublinha os laços de continuidade tanto com KerosSyros quanto com Grotta-Pelos.

No exame das relações das Cíclades com as diversas culturas do Egeu, com Creta, com a Anatólia e com a Grécia continental na Idade do Bronze Antiga, Renfrew sublinha a continuidade de contatos até o seu culminar no continuum cultural da Idade do Bronze II, da qual a cultura de Keros-Syros representa o aspecto cicládico. Segundo Renfrew, a razão da unidade expressa naquele continuum é o aumento da atividade dos prospectores, do comércio e da troca de informações sobre as técnicas da metalurgia. Ao invés de conjecturar invasões ou migrações, o verdadeiro problema a se estudar é o estanho, sobre o qual não se conhece qualquer veio no Egeu nem por centenas de quilômetros nas áreas circundantes. Ele constrói a hipótese de uma veia de estanho, subsequentemente extinta, perto de Troia, o lugar no Egeu onde o estanho é usado em tempos mais antigos e am maior quantidade.

Ao tratar os supostos contatos culturais entre as Cíclades e outras regiões do Mediterrâneo ocidental, a região balcânica, a Itália com as suas ilhas, Malta e a Península Ibérica, Renfrew apresenta todos os seus pontos fracos. A propósito das hipóteses de colônias egeias na Ibéria e da sua influência sobre as culturas neolíticas e calcolíticas ibéricas, identifica as maiores fraquezas da abordagem colonialista na ausência de uma cronologia absoluta e na argumentação viciosa: o material já classificado como colonial e não colonial constitui a prova decisiva usada pelos colonialistas a favor de sua tese. A aspiração da possibilidade de datar diversamente as culturas do Cicládico Antigo é introduzida por alguns acenos ao problema das datações em radiocarbono, ainda escassas. Renfrew entrevê a possibilidade de que um dia também esses deponham em desfavor do difusionismo "ex orient lux".

\subsection{Vias de transmissão cultural redesenhadas pela obsidiana}

Do estudos da obsidiana, um dos materiais objeto do apêndice da tese de doutorado, se desenvolvera um projeto mais amplo que conduzira Renfrew a intervir sobre a teoria geral do comércio pré-histórico. Nesse projeto é possível reconhecer a primeira tentativa de construir uma abordagem sistemática do mecanismo da transmissão cultural auspiciado já na tese de doutorado; é significativo que esse resultado seja obtido através da utilização das metodologias próprias das ciências naturais. 
Renfrew, em colaboração com J.R. Cann, pesquisador do Departamento de Mineralogia e Petrologia da Universidade de Cambridge, identifica um método de caracterização da obsidiana por meio de análises espectrográficas de traços de elementos ${ }^{8}$. Renfrew e seus colaboradores se propõem assim a estudar os contatos culturais na região do Mediterrâneo, superando a aproximação do método tradicional que examina semelhanças tipológicas entre os manufaturados e fornece por tal razão resultados incertos. Ao contrário, o estudo de uma matéria prima, que é um objeto de troca e do qual a proveniência precisa pode ser identificada, torna possível identificar com certeza a existência e os percursos das relações entre duas regiões (1964a). Os artigos nos quais Renfrew publica esse projeto, assim como aqueles sobre a caracterização de outros materiais nos mesmos anos, são afetados por modalidades retóricas típicas deste período marcado pelo entusiasmo pelo progresso científico (1965b; 1968b).

O aproveitamento da obsidiana de Melos desde o VI milênio a.C. demonstra um precoce e notável conhecimento das técnicas de navegações: se pode pensar que a difusão do modo de vida neolítico do Oriente Próximo à Europa possa ter ocorrido via mar, através do Egeu, antes do que via terra, através da Turquia, como quer a concepção tradicional. Além disso, as análises de caracterização de Renfrew demonstraram que o local de proveniência da obsidiana usada em Creta, sarapintada de pontinhos brancos, não é Lípara, mas Gyali, anulando assim uma prova de contato cultural e comercial entre Creta as Ilhas Eólicas (1965b).

$\mathrm{Na}$ investigação sobre a obsidiana no Oriente Próximo o escopo da pesquisa torna-se mais claramente a identificação dos mecanismos de comércio e de contato cultural (1966). A obsidiana é definida como um "indicador": não é o primeiro ou o mais importante objeto de comércio, mas aquele que permite uma reconstrução sobre bases científicas desde os tempos da revolução neolítica, uma vez que consistentes achados de obsidiana ocorrem em todos os mais antigos assentamentos agrícolas do Oriente Próximo, por quão distantes estes estejam das jazidas. Não se trata de um comércio organizado em uma rede regular de troca como é documentada na Idade do Ferro em diante: Renfrew sugere mecanismos de troca como aqueles em uso nas sociedades primitivas, onde a antropologia de campo documentou, por exemplo, o comércio de mercadorias e objetos sob a forma de troca cerimonial de dons ou de comércio silencioso.

Os resultados das análises espectrográficas documentam um tráfego de obsidiana da Capadócia em direção ao Levante e Jericó e da Armênia a Ali-Kosh através do Zagros, que remonta até o VIII milênio a.C., ao longo de vias de comunicações que deveriam ser conhecidas de tempos ainda mais antigos. A pesquisa sobre a obsidiana permite encarar o problema da localização da origem da revolução neolítica de modo diverso. As três regiões, certamente independentes do ponto de vista cultural, poderiam não sê-lo do ponto de vista tecnológico: as vias de obsidiana poderiam ter sido as mesmas ao longo das quais se transmitiam pouco a pouco os progressos tecnológicos simples e basilares - como ainda hoje a difusão de ideias tecnológicas ultrapassam confins culturais

8 A caracterização é o processo de identificação das propriedades de um material; ela torna-se útil na pesquisa
arqueológica porque permite associar uma amostra de material a uma fonte específica de proveniência. Renfrew ao
longo dos anos também explorará outros métodos de caracterização de materiais, veja RENFREW, 1971a; 1972c; 1976b. 
profundamente diversos. A rápida difusão da agricultura e do modo de vida neolítico nas três regiões que circundavam a planície mesopotâmica por volta de 6500 a.C., após milênios de contatos, o que é testemunhado pelo tráfego de obsidiana, não pode ser considerado o resultado de uma "revolução neolítica" como fenômeno independente, mas sobretudo o resultado de um processo gradual, complexo e cooperativo de troca de informações através daquelas vias antigas.

As análises de tipo quantitativo dos novos achados de obsidiana no Oriente Próximo apresentam traços regulares que permitem uma melhor compreensão dos mecanismos de comércio ou tráfego no Neolítico Antigo, assim como é possível reconstruir um "modelo", um mecanismo explicativo exprimível por meio de uma formulação matemática (1968a). Quando a quantidade percentual de obsidiana e a distância do sítio da jazida de proveniência são considerados sobre escala linear, se nota uma queda repentina e exponencial dos valores da percentagem de obsidiana a partir da distância de 300-400 quilômetros, enquanto entre essas distâncias os valores se mantêm mais ou menos constantes. Renfrew define a área compreendida entre a distância crítica "zona de contato" (contact zone), a área externa "zona de abastecimento" (supply zone). O uso das análises quantitativas é notoriamente arriscado nos estudos de arqueologia; por outro lado, defende Renfrew, mesmo se essas tentativas de interpretação possam e devam ser consideradas apenas hipóteses ("pois tais explicações sob a forma de leis são novas em arqueologia" [1968a, 330]), elas permitem colocar à prova as teorias elaboradas para explicar os mecanismos de troca pré-histórica.

\subsection{O encontro com a Nova Arqueologia}

O termo "modelo" aparece pela primeira vez no exame da obsidiana no Oriente Próximo (RENFREW, 1968b); encontra-se também no título de um artigo do mesmo ano, Models in Prehistory [Modelos na Pré-história] (1968b). Aqui, Renfrew discute os possíveis usos do termo em arqueologia indicando como exemplo o que se se faz dele nas ciências naturais, nas quais é costume reconhecer explicitamente os modelos nos quais apoiam-se as diversas teorias. Existem, segundo Renfrew, dois usos apropriados do termo "modelo": o primeiro é aquele de estrutura geral de pensamento dentro da qual se move o estudioso; o segundo é mais circunscrito: trata-se das explicações em forma de mecanismo ou esquema no qual se possam aplicar formulações matemáticas. Um exemplo é o modelo no estudo da obsidiana no Oriente Próximo (1968a).

Em 1968 são publicados também New Perspectives in Archaeology [Novas Perspectivas em Arqueologia] (BINFORD; BINFORD, 1968) e Analytical Archaeology [Arqueologia Analítica] (CLARKE, 1968). O primeiro contem os atos do convênio de Denver de 1965, consagração da Nova Arqueologia. Analytical Archaeology foi escrito por David Clarke, estudioso de Cambridge de alguns anos antes de Renfrew em seus estudos. Trata-se da primeira tentativa na Europa de desenvolver uma teoria autônoma da arqueologia9. Clarke, falecido prematuramente em 1976, deixou um grupo de jovens alunos que desenvolveram alguns pontos de seu pensamento. Models in Prehistory é o

9 Binford criticara Clarke por ter mantido um conceito de cultura similar àquele da escola histórico-culturalista de Childe (BINFORD 1972, p. 330-331). 
primeiro sinal da contribuição de Renfrew, ao lado de Binford e Clarke, para o desenvolvimento da arqueologia teórica, definida Nova Arqueologia. Renfrew mesmo atribuiu de passagem esse papel de passagem no artigo: a propósito da insatisfação difundida naqueles anos pela situação da arqueologia tradicional, contou como igualmente difusa era a vontade de dar à disciplina "uma sistematização mais coerente e teoricamente mais explícita" e como ele tinha "já publicado algo sobre a noção de modelo quando aparecem as obras mais importantes de Binford e Clarke" (1993b, p. 73) $)^{10}$.

É difícil encontrar uma definição bastante precisa e suficientemente compartilhada da Nova Arqueologia, que teve origem na colocação em discussão de muitos dos princípios e métodos então dominantes no estudo da pré-história, isto é, aqueles da escola histórico-culturalista. Muitos novos arqueólogos interpretaram o nascimento da arqueologia processual como a realização de uma típica revolução científica de acordo com a definição do historiador da ciência Thomas Kuhn (GUIDI, 1988, p. 160 ss.). No entanto, é verdadeiro que as contribuições expressas dentro da Nova Arqueologia variam muito quanto à metodologia e à abordagem teórica, tornando assim difícil considerá-la uma verdadeira e própria escola.

Nos Estados Unidos, no Reino Unido e nos Países Escandinavos, a Nova Arqueologia teve um grande número de seguidores; nela são reconhecidos a maior parte dos jovens estudiosos, os quais depois conquistaram importantes posições acadêmicas. Com a arqueologia processual se é assim constituída uma tradição 'transatlântica' (TRIGGER, 1978, p. 17), que uniu nas discussões e enfrentamentos contínuos em frequentes convênios a América do Norte e certos países do norte da Europa. Andrew Fleming deu uma ideia da importância do fenômeno para a arqueologia britânica quando disse do "crescimento e do desenvolvimento da arqueologia nas universidades britânicas como de um dos grandes sucessos dos últimos 25 anos" (FLEMING, 1996, p. 16).

Para preparar o papel de Renfrew como promotor da arqueologia processual contribuíra muitíssimo o período de estudo transcorrido nos Estados Unidos em 1966 na UCLA; ali estreitou relações com Binford e outros jovens estudiosos americanos. Por outro lado, no quadro da arqueologia processual, Renfrew buscou soluções aos problemas do modelo arqueológico históricoculturalista que the haviam sido colocados desde os tempos da pesquisa de doutorado.

Sobre a arqueologia processual um dos pontos de vista mais equilibrado é aquele de Alessandro Guidi, talvez justamente porque proveniente de um país periférico em relação ao centro do debate a respeito desse controverso momento da história do pensamento arqueológico. Guidi define a Nova Arqueologia através de seus componentes: existe um componente arqueológico, do qual fazem parte a herança de Childe, a abordagem econômica de Grahame Clark e a abordagem conjuntiva americana; um componente antropológico, no qual confluem a tradição funcionalista

\footnotetext{
10 A autora faz uma pequena confusão nas duas citações do parágrafo ao acomodá-las em seu raciocínio. Na primeira, na verdade, encontra-se na entrevista de Renfrew (1993b, p. 73) as seguintes palavras: "We wanted to systematize it in a more coherent, theoretically explicit, and in that sense 'scientific' way. [Queríamos sistematizá-la [a arqueologia] de uma maneira mais coerente, teoricamente explícita e, nesse sentido, 'científica'.". A segunda citação não está como citada na entrevista e decorre de uma interpretação das palavras de Renfrew. No texto, portanto, realizei a tradução das citações de acordo com as palavras de Ceserani para manter a fluidez do texto original (N.T).
} 
com aquela neo-evolucionista americana, caracterizada por uma concepção gradual das mudanças culturais; um componente filosófico-científico, que desenvolve elementos do positivismo, como a adoção do método hipotético-dedutivo de Hemel, mas inclui também a utilização da teoria dos sistemas e alguns elementos da cibernética; enfim, um componente matemático-estatística que busca transformar os dados empíricos da arqueologia tradicional em indicadores quantitativos (GUIDI, 1988, p. 160-167).

A adoção do método hipotético-dedutivo faz parte da busca por explicações sob forma de leis, sujeitas aos procedimentos de verificação, como exigem as ciências naturais. Um dos críticos mais ferozes das leis da Nova Arqueologia é o arqueólogo francês Paul Courbin: ele identifica como característica retórica que acompanha a procura das leis o gesto de adiar a um futuro indeterminado o processo de verificação (COURBIN, 1982). Esse traço retórico se encontra também nas conclusões do artigo de Renfrew sobre a obsidiana (1968a). É verdadeiro que naquele artigo a ambigüidade terminológica entre "lei" e "modelo" revela o desconforto de Renfrew diante da concepção rígida de leis e antecipa a via diversa que ele desenvolverá, dando vida à Nova Arqueologia britânica.

\subsection{Teoria de sistemas e comércio}

Trade and Culture Process in European Prehistory [Comércio e Processo Cultural na Pré-história Européia] (1969a) é o primeiro artigo no qual se encontram o uso dos instrumentos conceituais e o linguajar da Nova Arqueologia. É em certo sentido o ponto de chegada dos estudos sobre a caracterização da obsidiana, porém o plano da discussão se desloca ao comércio pré-histórico em geral.

Da Nova Arqueologia Renfrew deriva a crítica da concepção arqueológica tradicional das culturas como unidades, uma das quais pode 'influenciar' uma outra e induzi-la à mudança. Era a concepção de cultura de Childe, que sobre a equivalência de um dado conjunto de cultura material e um povo baseava as próprias hipóteses difusionistas. Inspirando-se na teoria geral dos sistemas, a Nova Arqueologia pensa as culturas como "agregados de sistemas, cada um dos quais varia independentemente" (1969a, p. 153): o centro da investigação torna-se agora o "processo cultural", ou seja, o funcionamento do sistema. Para explicar a mudança de uma cultura vale o funcionamento interno a ela e as relações entre os sistemas que a compõem. Renfrew coloca assim como momento central da mudança cultural o comércio, definido "o tráfego recíproco, a troca, ou o movimento de materiais ou bens através da agência humana pacífica” (1969a, p. 152).

A urbanização, ou proto-urbanização, do Egeu na Idade do Bronze Antiga é explicada por Renfrew em termos processuais: não com o desenvolvimento de um poder central, nem com influência externa, mas com um aumento imprevisto e marcado do comércio que produz uma nova riqueza, nova especialização artesanal, a difusão de armas e construções defensivas e um incremento da comunicação entre os assentamentos marítimos do Egeu. Renfrew conjectura uma correlação entre o desenvolvimento do comércio e a difusão da metalurgia: uma vez que a demanda de metal não podia ser atendida em um nível local em cada região, isto provocou uma intensificação da comunicação, através do comércio, em toda a área do Egeu. 


\section{3. $O$ aparecimento da civilização}

The Emergence of Civilisation [A Emergência da Civilização] (1972a) foi definido "o melhor exemplo da aplicação, da parte de Renfrew dos procedimentos interpretativos da Nova Arqueologia" (GUIDI, 1988, p. 179). Todos os componentes da definição da Nova Arqueologia se encontram por aqui, exceto o pensamento de Hempel: Renfrew se dissocia dele na introdução, sustentando que a arqueologia não descobre nunca as leis universais dos processos culturais.

A tese principal é de que seja possível explicar o surgimento da civilização minóica, a primeira civilização europeia, como resultado do desenvolvimento autônomo, do Neolítico em diante, das culturas do Egeu, sem precisar recorrer às migrações e às influências orientais conjecturadas pela arqueologia tradicional. Trata-se do desenvolvimento da tese de doutorado, da qual é utilizado o material e da qual deriva a ideia da importância da Idade do Bronze Antiga. Os problemas e as dúvidas, metodológicas e teóricas, da dissertação são, no entanto, superados: as perguntas são formuladas com decisão e os instrumentos para enfrentá-las são afinados por uma maturação aprofundada e pessoal dos conceitos da Nova Arqueologia. The Emergence of Civilisation é um texto fundamental tanto para os estudos de pré-história do Egeu quanto para a teoria arqueológica em geral ${ }^{11}$.

Antes de tudo, Renfrew enfrenta o problema da definição de "civilização", anteriormente (1969a) não claramente distinta à definição de urbanização. Sobre o modelo de "cultura" como conjunto de "meios de adaptação extra-somático do homem" (WHITE, 1959, p. 8), elabora uma definição essencial de civilização: "o complexo ambiente artificial do homem; ela é o isolamento criado pelo homem, um artefato que medeia entre si mesmo e o mundo da natureza" (1972a, p. 13). A comparação é com a nave espacial na qual os homens são encapsulados e isolados do contato direto com a natureza.

Renfrew identifica cinco subsistemas do sistema da cultura: subsistência, tecnologia, social, projetivo ou simbólico e o subsistema do comércio e da comunicação. Os princípios da cibernética identificam as relações entre os subsistemas explicando tanto a manutenção quanto a ruptura do equilíbrio de um sistema. Para explicar o aspecto conservador e a coerência da sociedade humana vale o mecanismo de feedback negativo, segundo o qual o sistema, em caso de perturbação, age para contrastar a força do distúrbio: em uma safra ruim para a colheita se procurará aumentar a quantidade de alimento através do comércio. Explicar a mudança cultural é mais difícil; o processo nesse caso é de feedback positivo, mais especificamente "deviation-amplifying mutual causal [desvio amplificador de causa mútua]": as mudanças em um subsistema influenciam um outro subsistema com uma mudança não apenas em escala de grandeza, mas na sua sua estrutura. Renfrew define esse processo "efeito multiplicador", por meio dele explica a emergência da civilização egeia ${ }^{12}$. Ele constrói duas possibilidades explicativas em cadeia causal: uma envolve os subsistemas de

\footnotetext{
11 A novidade na classificação do material cicládico em relação à dissertação está na utilização do método de análise de proximidade elaborado por Renfrew em colaboração com Gene Sterud (RENFREW 1969b) durante a permanência na UCLA. A pesquisa de métodos de análise multivariada é nesses anos típica dos novos arqueólogos, veja por exemplo BINFORD; BINFORD, 1966.
}

12 Renfrew cunha o termo de "efeito multiplicador" para esse processo identificado por Mayurama (1963). 
subsistência/redistribuição, a outra aqueles de especialização artesanal/riqueza, e demonstra a validade de ambos. Isso não deve surpreender: trata-se de uma consequência da complexidade e, portanto, da riqueza do sistema cultural. Nenhuma explicação em cadeia causal - nem mesmo aquela concentrada sobre o comércio proposta precedentemente (1969a) - é suficiente por si mesma para explicar um fenômeno tão complexo quanto o surgimento da civilização humana. Se uma explicação total é impossível, aquilo que mais se aproxima é o efeito multiplicador que coloca em jogo as interações positivas entre todos os subsistemas examinados e, portanto, resolve a fraqueza das explicações em cadeia causal, expressa na pergunta "que coisa causou a causa?". Além disso, o efeito multiplicador permite mover a discussão da sociedade ao indivíduo: é, de fato, a capacidade humana de realizar atividades em todos os diversos subsistemas que coloca em movimento os mecanismos de feedback positivo. Tomando em consideração o fator humano se entende a importância da equivalência entre valores sociais e valores materiais estabelecida no terceiro milênio no Egeu. Por exemplo, a introdução das armas não se explica sem dar o devido reconhecimento ao fator competitivo, assim como para explicar a estratificação social é necessário reconhecer a importância do desejo de prestígio e o princípio que o prestígio é ligado à riqueza, e assim por diante.

A explicação processual da origem da civilização egeia, profundamente diversa da explicação da arqueologia tradicional, representa o ponto de chegada da busca de uma alternativa à concepção de Childe, iniciada com a tese de doutorado. Os colonos orientais conjecturados por Childe em The Dawn of European Civilization (1925), os artífices e prospectores que, provenientes das sociedades totalitárias orientais, chegam como emigrantes naquela egeia igualitária, dando origem e explicações à qualidade única da civilização europeia em The Prehistory of European Society [A Pré-história da Sociedade Europeia] (1958), são muito distantes das análises do processo cultural realizadas por Renfrew. A ideia de uma revolução, primeiramente neolítica e depois urbana, nascida no Oriente e transportada para a Europa, é substituída pela ideia de um processo longo, cuja inteira duração corresponde à revolução ${ }^{13}$. Courbin, novamente o crítico mais feroz, elogia o livro já que ele contem "um excelente (mas tradicional) estudo das Cíclades" e mantém, no entanto, que a tese proposta para explicar a origem da civilização é em última análise bastante trivial (COURBIN, 1982, p. 117; p. 59). Creio que seja inegável que o livro de Renfrew tenha aberto uma nova área de estudo, a idade do Bronze Antigo no Egeu, e tenha convencido outros estudiosos, sobretudo das novas gerações, a se colocarem problemas novos, e não somente de tipo descritivo. Por esses mesmos jovens estudiosos, alguns dos aspectos do trabalho de Renfrew foram submetidos sucessivamente à crítica. A inovação terminológica foi criticada pois não parece que se possa falar de culturas discretas no curso do Cicládico Antigo (COLEMAN, 1979b; BARBER; MacGILLIVRAY, 1980). Foi criticado o poder explicativo

\footnotetext{
13 "A operação do efeito multiplicador - de situações de feedback positivo dentro e entre subsistemas acoplados - produz uma 'revolução' no sentido pretendido por Gordon Childe. Isso se aplica igualmente para a revolução Neolítica, Urbana e Industrial. Cada uma pode durar um longo tempo para maturar, uma vez que essas não são repentinas mudanças quânticas, mas processos contínuos de mudança. Porém em cada caso a taxa de inovação e a velocidade das mudanças estruturais nas sociedades são muito mais rápidas durante um considerável período, o que consideramos como a duração da própria revolução." (RENFREW, 1972a, p. 43.) (N. T.).
} 
atribuído ao fator tempo em si no conceito da mudança gradual e foi aberta uma reflexão sobre uma visão da história concentrada sobre as mudanças lentas e incrementais (CHERRY, 1983).

O efeito multiplicador representa as características típicas das explicações de Renfrew; é derivado de uma outra disciplina (nesse caso a cibernética) e é generalizável. Pode explicar as origens de outras civilizações, as suas qualidades formais fazem-no aplicáveis também fora do contexto do Egeu. Quando, anos mais tarde, o próprio Renfrew criticará o efeito multiplicador (1982a), manterá a apreciação por seu caráter de generalização. Enquanto Renfrew declara dissociar-se das leis universais (1972a, p. 16), não aprofunda as implicações da sua concepção de explicação: em base a quais definições de cultura pode uma explicação elaborada em função dos dados oferecidos por um dado contexto ser aplicada em um outro contexto cultural?

\subsection{Antes da civilização}

Before Civilisation: the Radio-Carbon Revolution and Prehistoric Europe [Antes da Civilização: a Revolução do Radiocarbono e a Europe Pré-histórica] (1973a) é o livro de Renfrew que teve até agora maior difusão, traduzido em japonês, francês, espanhol e italiano. Fruto de reflexões e estudos de anos, propõe um novo paradigma para a arqueologia pré-histórica do continente.

A arqueologia tradicional significa ainda mais uma vez a obra de Childe. A cronologia tradicional era estreitamente conectada à concepção difusionista das sínteses de Childe, baseadas sobre o princípio de que "cada invenção foi feita apenas uma vez" (CHILDE, 1956): as relações entre as culturas vêm identificadas através de paralelismos tipológicos, transformados pela aplicação dos princípios difusionistas em paralelismos cronológicos. O sistema cronológico tradicional estabelece assim para as culturas europeias uma série de conexões a partir do Egeu, cujo paralelismo com o Egito estabelece as datações de calendário como partida, enquadrando-as em um todo único de 3000 a.C. em diante.

Também no novo paradigma proposto por Renfrew encontra-se uma ligação estreita entre a concepção da pré-história europeia e a cronologia. É justamente a partir da cronologia que Renfrew inicia sua crítica. $O$ estudioso coloca em discussão a dependência das culturas ibéricas da civilização egeia (1967a): trata-se de um desenvolvimento da crítica dos paralelismos tipológicos entre as duas regiões já conduzida na tese de doutorado. Renfrew discute depois a ligação Wessex-Micenas, sobre a qual baseava-se a datação da Idade do Bronze Antiga da Europa central e setentrional (1968c). Outro nexo discutido (1969c) é aquele estabelecido entre a cultura de Troia I e a cultura de Vinča na Iugoslávia, utilizado tradicionalmente para demonstrar a dependência das culturas metalúrgicas dos Balcãs do desenvolvimento da Idade do Bronze do Egeu e o papel do Danúbio como canal de difusão natural em direção ao coração da Europa.

Elemento decisivo foram os resultados da calibração do radiocarbono. Renfrew foi o primeiro dentre os arqueólogos a entender sua importância para a pré-história europeia; a utilizar e a difundir seus resultados no mundo da arqueologia. A primeira curva de calibração foi apresentada pelo estudioso americano H. E. Suess em 1967 durante um congresso em Munique. Já em 1970 Renfrew 
procura delinear o quadro geral que está emergindo das datas europeias calibradas (1970a; 1970b). A nova cronologia calibrada desenha como uma linha de falha que corta em dois o Mediterrâneo: de uma parte o Oriente Próximo, o Egeu e a Anatólia, de outra os Balcãs, a Itália, Malta, a Ibéria e o resto da Europa. Enquanto dentro destas duas áreas as relações cronológicas tradicionais entre as diversas culturas são confirmadas pela cronologia calibrada para radiocarbono, os paralelismos cronológicos entre as duas áreas são completamente contraditórios. A discrepância se verifica nos supostos paralelismos culturais que Renfrew já tinha colocado em discussão com argumentos puramente arqueológicos antes que as datas calibradas para radiocarbono estivessem disponíveis. "A simples moral que podemos tirar hoje é que um desenvolvimento geral paralelo em diferentes regiões não implica necessariamente nenhum contato entre elas." (1970a, p. 291) 14. $^{14}$

A exigência de continuidade com a alta tradição das contribuições de Childe manifestase na preocupação de Renfrew em manter a concepção de uma pré-história europeia como um quadro único e coerente. A imagem que Renfrew utiliza para ilustrar o novo quadro é, de fato, um mapa da Europa com as linhas dos isócronos. O conceito de "isócrono" é uma invenção de Childe; é representado pela linha que encerra o espaço de difusão da metalurgia no período indicado. A representação da Europa de Childe havia desenhado linhas concêntricas mais amplas; no mapa de Renfrew existem diversos epicentros de linhas concêntricas em expansão para indicar as invenções independentes umas de outras dos processos que conduzem à metalurgia.

Renfrew começa a examinar o novo quadro caracterizado pela autonomia cultural com os instrumentos da escola processual (1970b): no centro da investigação arqueológica não estão mais os artefatos, mas os processos culturais que os produziram; é necessário começar a pensar em termos quantitativos, a fim de formular hipóteses verificáveis no confronto com os dados arqueológicos.

O caso da calibração das datas para radiocarbono é um ótimo exemplo da capacidade de Renfrew de integrar as inovações científicas ao estudo do passado. Os riscos de uma confiança excessiva na capacidade de resolução das ciências naturais estão, porém, presentes em um artigo seu onde a relação entre Wessex e Micenas é negada (1968c). Renfrew data a cultura de Wessex sobre a base das poucas datas calibradas então disponíveis para Stonehenge, quando a relação entre as duas é de toda hipotética; comparando igualmente as datas calibradas do norte da Europa com as datas históricas do Egeu derivadas do paralelismo com o Egito, compara entre si datas heterogêneas, operação de coerência discutível. As datas subsequentemente obtidas para a cultura Wessex confirmaram, no entanto, que um paralelismo entre o desenvolvimento da cultura de Wessex e aquela micênica é cronologicamente possível ${ }^{15}$.

Em Before Civilization Renfrew define como "revoluções" as mudanças da cronologia tradicional: "a primeira revolução do radiocarbono" e "a segunda revolução do radiocarbono",

\footnotetext{
$14 \quad$ Childe mesmo era em um certo sentido consciente dos problemas de sua cronologia: em uma aula realizada em 1938, ele tinha já exposto dois possíveis esquemas cronológicos para a pré-história europeia, um dos quais assemeIha-se incrivelmente ao quadro defendido por Renfrew; Childe havia escolhido o outro sobre a base da convicção que as culturas europeias sempre estivessem estado em retardo em relação ao Oriente Próximo (CHILDE, 1938).

15 Muitos dos artigos que eu discuti como passos do percurso foram publicados em uma coletânea comentada pelo próprio Renfrew (RENFREW, 1979a).
} 
ou seja a calibração que foi mais incisiva. Delineia assim o projeto, elaborado a partir da Nova Arqueologia, de uma arqueologia social: para interpretar as evidências arqueológicas se tomam em consideração as configurações sociais específicas que as produziram. Os instrumentos são os estados de demografia, da organização econômica, de paralelos etnográficos, da hierarquia social. As relações mais impressionantes da Europa pré-histórica são passadas ao crivo da abordagem processual-social: os megalíticos, os templos malteses, a metalurgia dos Balcãs, a emergência da civilização minóico-micênica e Stonehenge.

Como exemplo vale a análise do fenômeno dos megálitos: depois da calibração resultam ser as primeiras tumbas neolíticas de seu tipo no mundo inteiro. A hipótese de Renfrew é que a sua função fosse aquela de fornecer o único elemento de estabilidade em um tipo de existência fundado sobre a agricultura itinerante. A hipótese é confirmada da distribuição espacial dos megálitos: nas ilhas Órcades é claríssimo que eles respondem a uma divisão da terra agrícola. A capacidade de mobilização da força de trabalho necessária às suas construções é determinada pelo contexto social e pode ser explicada através de paralelos etnográficos. Esse confronto serve para entender como pequenas comunidades, que vivem logo acima do nível de subsistência, podem cooperar em empresas assim grandiosas.

O último problema para explicar é a distribuição dos megálitos na Europa ao longo da costa do Atlântico, onde param, defronte ao mar, a "onda de avanço" do modo de vida neolítico e onde os imigrantes que introduzem a agricultura encontram a economia mesolítica das populações locais. Nasce uma nova riqueza e uma densidade populacional maior.

As interações entre os imigrantes agricultores neolíticos e a população mesolítica local existente, conforme essas adotavam práticas agrícolas, criaram o interesse particular na demarcação de territórios, na demonstração de solidariedade do grupo e na competição tribal, que as tumbas megalíticas refletiam (1973a, p. 147).

\subsection{Os modelos em arqueologia}

Depois do primeiro período de compacta afirmação polêmica e programática, no curso dos anos sessenta a produção dos novos arqueólogos se diferencia (KLEJN, 1977; CUOMO DI CAPRIO, 1986b; GUIDI, 1988). As rachaduras na coesão de grupo resultam também do intensificar-se da discussão teórica; a partir do final da década afirmam-se novas correntes, que criticam a arqueologia processual. Renfrew inicia um percurso de pesquisa pessoal, caraterizado pelo empenho contínuo na criação de novas hipóteses e pela disponibilidade a mudanças de ideia; no centro está a elaboração da arqueologia social e a aplicação da abordagem através de modelos.

$\mathrm{Na}$ arqueologia britânica os anos setenta abrem-se com debate sobre os modelos. Dois livros (CLARKE, 1972; RENFREW, 1973b) organizados pelos dois jovens arqueólogos mais promissores, que reúnem uma quantidade enorme de contribuições, atestam a centralidade da função dos modelos como instrumentos heurísticos fundamentais da interpretação arqueológica e da interdisciplinaridade inerente em sua utilização; os arqueólogos trazem inspiração das várias disciplinas: a antropologia, a ecologia, a geografia, etc. 
O volume organizado por Renfrew (1973b) reúne as atas do congresso por ele organizado em 1971 em Sheffield, onde no entretempo ele tinha sido chamado como lecturer. Trata-se de oitenta e quatro contribuições de abordagens teóricas díspares, nas quais o debate entre os novos arqueólogos e os não novos arqueólogos é ardoroso. No discurso final, o antropólogo Edmund Leach denuncia a atitude anacrônica dos arqueólogos que, querendo utilizar modelos antropológicos, se apoiam na metodologia funcionalista superada na antropologia então há tempos por aquela estruturalista (LEACH, 1973): é evidente a crítica de um dos aspectos fundamentais da interdisciplinaridade proposta por Renfrew.

Em sua contribuição Renfrew (1973e) se propõe a explicar o fenômeno dos monumentos pré-históricos da cultura de Wessex, dos túmulos em Stonehenge. Enquanto o difusionismo os explicava como resultado de uma obra de artesãos orientais, provenientes de uma cultura superior, Renfrew utiliza o modelo do chiefdom [chefia], derivado do antropólogo neo-evolucionista Elman Service (1966). A distribuição espacial dos monumentos sugere, como sua função, aquela de demarcar o território das várias chefias. Com base na tipologia dos monumentos neolíticos, Renfrew reconstrói um quadro hipotético da emergência das chefias no Neolítico Antigo, que se desenvolvem plenamente no tempo dos monumentos de tipo henges, até resultarem em uma chefia unificado com quatro ou cinco sub-regiões no tempo de Stonehenge III.

A concepção de "modelo" tornou-se mais complexa: não se trata de apenas um esquema no qual é aplicável uma formulação de tipo matemática (1967a), mas de um instrumento para construir uma moldura de referência abstrata na qual seja possível comparar situações culturalmente diferentes. Enquanto para Clarke os modelos são importantes na medida em que permitem colher nos desvios da norma as características específicas dos casos particulares, Renfrew está interessado na formalização como instrumento da comparação e na pesquisa dos modelos de valor geral. A tendência de Renfrew em pensar os problemas arqueológicos em sentido generalizante é acompanhada por uma atividade de arqueólogo de campo notável pela variedade dos sítios: do Egeu às ilhas Órcades e às regiões balcânicas (1968d, 1982b, 1985a, 1985c, 1986e). A abordagem através de modelos é o que caracteriza Renfrew: trata-se de sua alternativa à pesquisa de leis universais da Nova Arqueologia. Todavia, a confiança na generalização dos modelos comporta tanto problemas quanto a universalidade das leis. Além disso, Renfrew arrefece o contato com o material arqueológico de base, justamente enquanto os novos arqueólogos americanos concentram sua atenção nele com a busca das middle range theories - teorias de médio alcance dedicadas aos processos de formação da própria evidência arqueológica (BINFORD, 1977, p. 1-10).

Em 1973 Renfrew torna-se professor em exercício em Southampton. Na aula inaugural reafirma sua concepção da arqueologia como "a reconstrução da organização social de sociedades passadas, e a forma que elas olhavam para o mundo" (1973c, p. 7.). Ao lado da concepção expressa em Before Civilization acrescenta-se aqui como elemento importante o estudo dos esquemas de assentamento, que correlaciona as plantas dos assentamentos pré-históricos com o sistema sócio econômico.

Renfrew organiza o volume British Prehistory: a New Outline [Pré-história Britânica: um Novo 
Esboço] (1974e), uma coleção de ensaios de especialistas dos vários períodos da pré-história da Grã-Bretanha que levam em consideração as novidades trazidas pela calibração do radiocarbono. $\mathrm{Na}$ introdução Renfrew delineia com grande diplomacia uma história da paleoetnologia britânica na qual aparece clara a aspereza do debate em curso:

Em um momento no qual os pré-historiadores estão enfatizando as continuidades de desenvolvimento nas culturas do passado, ao invés de mudanças repentinas produzidas por influências externas, é apropriado também reconhecer a continuidade de nossa própria disciplina.

O livro, de fato, é dedicado aos três grandes estudiosos da tradição pré-histórica britânica: Grahame Clark, Christopher Hawkes e Stuart Piggott. Renfrew subdivide a história dos estudos sobre a pré-história britânica em três fases: a terceira, aquela do estudo do processo cultural, supera, com a ajuda das novas datações em radiocarbono, os limites das explicações difusionistas oferecidas pela arqueologia das culturas e das invasões (1920-1960), assim como essa última tinha quebrado, introduzindo em um modo sistemático as variações espaciais, os esquemas da arqueologia baseadas sobre a divisão do passado em épocas e períodos (1860-1920).

\subsection{Modelos de distribuição espacial}

O interesse principal na reflexão de Renfrew continua a ser o processo de mudança cultural: o tipo de modelos utilizados se amplia e se complexifica. Um percurso deriva da afirmação do conceito de autonomia cultural, passa pela sucessiva adoção da abordagem sistêmica e conduz aos modelos de troca.

Em Trade as an Action at Long Distance [Comércio como uma Ação a Longa Distância] (1975a) encontram-se condensadas as teorias do estudioso sobre a mudança cultural, sobre o emergir da civilização e sobre o comércio pré-histórico e aquele derivado dos estímulos da escola do substantivismo econômico e da geografia localizacional. Renfrew propõe uma análise tanto do comércio quanto da civilização em termos de organização espacial, de modo a poder demonstrar a importância do comércio na formação da própria civilização. Segundo essa hipótese, preliminar ao nascimento da civilização é a presença de um certo número de localidades centrais permanentes nas quais se concentram as relações e as atividades dos habitantes de uma região. Originariamente em cada lugar central corresponde um certo território, definido ESM, "Early State Module [Módulo do Estado Inicial]". A interação entre os ESM produz e mantém a uniformidade cultural que constitui a civilização. As áreas onde esse modelo é testemunhado são: a Grécia micênica, a Creta minóica, a civilização Maia, a Mesopotâmia, a Nigéria, a Etrúria.

O comércio representa o aspecto material e, portanto, arqueologicamente interrogável, da interação entre os ESM. Renfrew propõe analisar as distribuições espaciais produzidas pelos 10 modos de comércio: 1) o acesso direto; 2) a reciprocidade home-base; a reciprocidade com encontro nas fronteiras; 4) o comércio down-the-line, isto é, através diversos territórios por meio de trocas sucessivas; 5) a redistribuição a partir do lugar central; 6) a troca de mercado a partir do lugar central; 7) o comércio por meio de intermediários; 8) o comércio por meio de emissários; 9) o 
enclave colonial; 10) o porto franco. A reciprocidade se realiza na distribuição espacial em uma longa série de trocas sucessivas a partir da fonte: os pontos equidistantes a partir da origem apresentam a mesma quantidade de material. A redistribuição a partir de um lugar central destrói a simetria da reciprocidade. O comércio free-lance é revelado pelo fato de que cada intermediário tem uma área afetiva de operações além dos limites da qual ele não ultrapassa.

Sobre essa correlação Renfrew volta-se criticamente (1977a): de um atento exame resulta que modos de comércio tão diversos como a redistribuição a partir do lugar central e a troca de mercado produzem distribuição espaciais idênticas. Renfrew formaliza e desenvolve igualmente um modelo para a troca a partir do comércio em situações de reciprocidade. Utilizando os dados obtidos da caracterização científica dos materiais, representa em um gráfico a quantidade de material em um sítio em função da distância da fonte. Renfrew define, portanto, a "lei do decrescimento monotônico": a curva de frequência, isto é, a ocorrência de uma mercadoria trocada, decresce em relação à distância da fonte, ou seja, a quantidade de produto trocado diminui em relação ao aumento da distância da fonte da matéria prima. Situações particulares determinam curvas diversas de regressão no gráfico: por exemplo, um percurso casual ou de fuga determina uma linha de queda de tipo gaussiano. Um futuro promissor é oferecido pelo estudo dos meios de organização por meio dos quais a lei de decrescimento monotônico é violada pelos sistemas de troca humana, sobretudo por aqueles organizados hierarquicamente. Essa lei apresenta algumas das características das leis da Nova Arqueologia americana: em um certo sentido trata-se de um truísmo símile àqueles das assim chamadas "Mickey Mouse laws" (COURBIN, 1982, p. 80), porém ao colocar acento sobre as variações da norma Renfrew redime a aparência de banalidade: nesse sentido o adiamento a estudos futuros torna-se profundamente diverso do gesto retórico de adiar a um futuro indeterminado a verificação das leis ${ }^{16}$.

É interessante notar o papel do comércio. Na arqueologia tradicional o comércio era em um certo sentido a solução para explicar a mudança cultural; com base na importação de artefatos ou no paralelismo tipológico se conjecturava contatos culturais e assim influxos de uma cultura sobre outra. No quadro dominado da autonomia cultural, Renfrew procura indagar e explicar o comércio em si, como motivo interno do processo cultural. Os antropólogos, contudo, não tardam em notar que a tentativa de quantificar os dados peca por uma rigidez em que escapam aspectos importantes da atividade humana (ADAMS, 1974).

\subsection{Mudança cultural e modelos de transformação}

A pesquisa de modelos adaptados para explicar a mudança cultural impulsiona-se em direção a zonas mais insólitas à frequentação arqueológica em Transformations: Mathematical Approaches to Cultural Change [Transformações: Abordagens Matemáticas para a Mudança Cultural] (1979b). A matemática, defende Renfrew, oferece modelos simples e facilmente generalizáveis: no sexto capítulo (1979c) ele fornece um exemplo, um gráfico "em tenda" que permite, inserindo no computador os dados das fronteiras de um território, das dimensões dos assentamentos em seu interior e

16 Esse gesto retórico é discutido por Courbin (1982, p. 45); um exemplo já citado é RENFREW, $1967 a$. 
das distâncias entre eles, identificar a organização sociopolítica da região. Na tenda radialmente simétrica, a altura do poste central está para as dimensões da maior localidade e somente os centros menores cujas "tendas" estão compreendidas dentro daquela maior localidade estão sob sua influência política, enquanto as outras estão fora. Trata-se de uma lei de decrescimento monotônico aplicada à influência política.

A fascinação de Renfrew pela abordagem matemática é ligada sobretudo aos modelos morfogenéticos, em particular à teoria das catástrofes de René Thom, sobre a qual já tinha publicado um artigo (1978g). A matemática, assim com as simulações computacionais (1981c), produzem modelos nos quais estão envolvidos aumento de medida, número, complexidade e nos quais é a própria estrutura a desenvolver regras próprias e novas propriedades.

No último capítulo do livro (1979c) a teoria das catástrofes, segundo a qual a mudança catastrófica advém depois que o sistema procurou manter-se o mais tempo possível sem mudanças, vale para explicar o colapso de algumas sociedades estatais antigas, um fenômeno imprevisto através do qual uma sociedade florescente desaparece das evidências arqueológicas; é o caso da queda da civilização micênica, da civilização palacial minóica, da civilização do Vale do Indu, do império hitita, do Primeiro Período Intermediário egípcio, da civilização clássica Maia, etc.

O modelo das catástrofes também traz à luz propriedade úteis e implicações imprevistas. A anástrofe, o caso simetricamente oposto à catástrofe, pode ser usada para explicar o surgimento da sociedade estatal. O tipo da catástrofe borboleta, que se exprime como uma dobradura do gráfico tridimensional, sugere uma realização trimodal, inserindo a sociedade de tipo chefia ao lado daquela simples igualitária e daquela de tipo estatal ${ }^{17}$.

Essa utilização da teoria das catástrofes é exemplo típico da construção de um modelo de Renfrew: ela permite a comparação dos processos de mudança na pesquisa de regularidade intercultural. Na construção elaborada de Transformations se lê também a tentativa, dentro da abordagem sistêmica, por si só anti-evolutiva, de explicar a mudança sem envolver causas externas (CAZZELLA, 1985, p. 191; KLEJN, 197, p. 23), como já tinha sucedido com o "efeito multiplicador". Trata-se de um fio que atravessa toda a obra de Renfrew, consequência necessária do conceito de autonomia cultural. Na consequente ideia de trajetória cultural se encontra um outro rastro da concepção histórica e da exigência de síntese que caracterizam Renfrew dentro da Nova Arqueologia e que o revela herdeiro da tradição arqueológica europeia (TRIGGER, 1989b, p. 320; p. 316-317).

\subsection{Reconsiderações}

Os temas de Transformations são retomados na terceira parte do volume Theory and Explanation in Archaeology [Teoria e Explicação em Arqueologia] (1982a), isto é, as atas do segundo congresso da Theoretical Archaeology Group [Grupo de Arqueologia Teórica] (TAG) realizado em 1980 em Southampton. Dentre as diversas contribuições, verifica-se que agora na arqueologia teórica,

17 Muitos dos ensaios que analisei como exemplos da abordagem social de Renfrew encontram-se também reunidos e comentados por ele mesmo em RENFREW, 1984 . 
nascida como processual, estão representadas escolas diversas e posições diferentes. Na introdução, Renfrew (1982a) examina as diversas escolas, "os ismos de nosso tempo": existem explicações de tipo histórico (o evento é analisado em sua particularidade mais do que de acordo com uma abordagem nomotética e generalizante); no extremo oposto, estão as explicações fornecidas da abordagem hipotética-dedutiva; numerosos estudos arqueológicos usam, no entanto, a teoria dos sistemas (ou ao menos alguns termos úteis de seu vocabulário: "feedback", "homeostase" etc); a abordagem neo-marxista fornece explicações ainda diversas (mais do que uma forma precisa de explicações, tratar-se-ia de demonstrar que eventos e processos operam em conformidade com o modelo de Marx); o último dentre os "ismos" da arqueologia ocorridos é, finalmente, o estruturalismo. As melhores explicações, defende Renfrew, trazem um esquema dos dados arqueológicos e analisam o mecanismo pelo qual o próprio esquema é governado. Um exemplo é o modelo down-the-line para o fenômeno da queda exponencial da quantidade de bens comerciais com a distância (1967a). Mais difícil é explicar um processo complexo como a formação do Estado ou o nascimento da cidade. Renfrew critica também a própria aplicação do nascimento da civilização egeia (1977a):

[A própria empreitada de construir um] modelo ou explicação de complexidade suficiente para lidar com múltiplas variáveis envolvidas resulta em um construto tão elaborado que sua simplicidade explicativa e força são diminuídas.

Nas conclusões, reafirma a oportunidade de explicar dados e fenômenos em termos generalizantes, o que comporta uma vontade de pesquisa comparativa e transcultural.

Na celebração do centenário do Archeological Institute of America [Instituto Arqueológico da América] em 1979, a intervenção de Renfrew despertou comoção: The Great Tradition versus the Great Divide [A Grande Tradição versus a Grande Divisão] (1980b) convidava o Archeological Institute of America, ligado à tradição classicista da arqueologia, a abrir-se às novas técnicas científicas, ao desenvolvimento de novas ideais e de uma teoria consciente e explícita para não correr o risco de representar uma tradição nobre, mas fora do tempo. Binford é definido como o arqueólogo mais influente do século ${ }^{18}$.

\subsection{A interação}

A partir do início dos anos oitenta aparecem nos estudos de Renfrew modelos de explicação diversos daqueles estritamente sistêmicos e talvez um pouco rígidos dos anos setenta; neles se percebe uma maior atenção à história e às relações de estrutura.

An Island Polity: the Archaeology of Exploitation in Melos [Uma Unidade Política Insular: a Arqueologia de Exploração em Melos] (1982b), nascido do projeto de pesquisa por ele conduzido na ilha, é muito diverso de Emergence of Civilisation: reúne as competências de uma équipe de especialistas em várias disciplinas, da economia a geologia. Na conclusão, a história de Melos é vista

18 Anthony Snodgrass responde a essa intervenção, abrindo um debate sobre a Nova Arqueologia e a arqueologia clássica, para a qual veja SNODGRASS, 1985; 1987; DYSON, 1981; 1993; MORRIS, 1994. 
como processo no qual desempenham os fatores do aproveitamento concomitante ao nascimento de um poder central, da intensificação da produção e da interação entre as diversas unidades socioculturais (polities). É explícita a tentativa de analisar as dinâmicas da mudança cultural usando uma única unidade territorial delimitada. Um resultado do trabalho é a constatação que a expansão territorial não é um fator necessário no processo de formação de um Estado mesmo que essa pareça ser uma componente inevitável das suas consequências, como Melos teve que aprender às próprias custas.

O mesmo tipo de abordagem emerge claramente em dois volumes organizados por Renfrew nos anos oitenta. Na introdução do primeiro, Ranking, Resource and Exchange [Ranqueamento, Recurso e Troca] (1982f), Renfrew defende que a melhor abordagem na investigação da mudança cultural seja a concentração das atenções sobre dois processos somente: a intensificação da produção (os progressos tecnológicos considerados sistematicamente e com seus correlatos sociais) e a interação entre comunidades paritárias. Deve, portanto, ser privilegiado o estudo dos efeitos desses processos um sobre o outro e sobre estruturas sociais ${ }^{19}$.

Ao segundo processo é dedicado Peer Polity Interaction and Socio-Political Change [Interação de Unidades Políticas Paritárias e Mudança Sociopolítica] (1986a). Na introdução, Renfrew delineia o conceito de interação entre comunidades paritárias: ele compreende todos os gêneros de troca entre as unidades sociopolíticas autônomas, superando assim a dicotomia entre a ideia de mudança exógena e endógena. Esse conceito, um dos mais profícuos dentre aqueles elaborados por Renfrew, aparentado com os Early State Modules (1975a), resolve em um certo sentido a tensão entre autonomia cultural e influências externas ${ }^{20}$. A autonomia cultural na forma extrema em que Renfrew havia primeiramente apresentado como alternativa ao quadro da Europa de Childe (1973a), é propriamente o aspecto de sua obra mais criticado pelas novas gerações, que buscam integrar novamente a ideia de relações entre culturas diversas no Mediterrâneo e na Europa, percorrendo novamente algumas das vias delineadas por Childe (SHERRATT, 1996; 1998).

\subsection{A arqueologia da mente no Egeu}

Durante as escavações em Melos são trazidos à luz alguns restos interpretados por Renfrew como evidências de um santuário de época micênica (1978a), o assim chamado santuário de Phylakopi, que o conduziu ao estudo da religião pré-histórica, argumento para ele novo. Ao

19 A intervenção de Binford (1982) como conclusão do volume sinaliza também a separação dos percursos da arqueologia americana e britânica: de fato, ele mantém que esta última tenha permanecido substancialmente ligada às concepções tradicionais historicistas, limitando-se a revesti-las de termos novos. Os modelos de Renfrew são, no juízo de Binford, construções de imagens descritivas do passado, sem nenhuma atenção aos problemas de interpretação das evidências arqueológicas. Veja também TRIGGER, 1989a, p. 318.

20 A interação paritária foi também o tema da primeira aparição de Renfrew, e da Nova Arqueologia, na Itália (RENFREW, 1986f). Aqui a presença do debate sobre a Nova Arqueologia foi tardio e marginal, o que algumas vezes permitiu na distanciamento considerações críticas bastante penetrantes. Veem citados: BIETTI SESTIERI, 1985, crítica da arqueologia social de RENFREW, 1984a; CAZZELLA, 1985, intervenção muito crítica; CUOMO DI CAPRIO, 1986a; 1986b, intervenções que discutem o escasso interesse italiano ao problema; GREPPI OLIVETTI, 1982, análise interessante; GUIDI, 1988, já muito citado. Com relação ao uso dos modelos propostos por Renfrew, veja a análise de AMPOLO, 1986. 
apresentar o material de Phylakopi em uma conferência dedicada aos santuários da Idade do Bronze do Egeu, o estudioso colocou o acento sobre a potencialidade oferecida por esse material para uma análise arqueológica contextual: aos achado pode-se atribuir função e significado por meio da cuidadosa análise dos contextos e das associações, em vez da muito mais fácil aplicação dos esquemas derivados da interpretação dos materiais privados de contexto provenientes de outras escavações ou de práticas documentadas para o período mais tardio. É possível assim construir esquemas interpretativos confiáveis e com valores generalizantes, utilizáveis também fora do Egeu (1981a).

\subsection{A teoria para uma arqueologia da mente}

A partir das reflexões sobre a abordagem da arqueologia ao estudo da religião pré-histórica, Renfrew chega à construção de uma teoria arqueológica que leva mais em conta o aspecto cognitivo da atividade humana. A primeira ocasião para uma apresentação pública dessa temática foi a leitura inaugural que Renfrew pronunciou em ocasião de sua chamada à Universidade de Cambridge em 1982 como Disney Professor of Archaeology, a cátedra mais prestigiosa do mundo da arqueologia pré-histórica britânica. Em Towards an Archaeology of Mind [Para uma Arqueologia da Mente] (1982e) é exposto o problema da arqueologia cognitiva, ou arqueologia da mente, que se ocupa do comportamento intelectivo dos homens e de como reconhecê-lo a partir dos dados materiais.

Renfrew encara o desafio da arqueologia da mente em uma perspectiva de história da arqueologia. Nesse desenvolvimento, o momento mais importante, após Darwin, foi a consciência teórica si, alcançada pela arqueologia nas obras de Binford e Clarke com a Nova Arqueologia, que tornou possível a ampliação do campo de pesquisa arqueológica, como é claríssimo no caso da arqueologia social.

A possibilidade, escreve Renfrew, de usar os materiais arqueológicos para formular deduções e inferências sobre os processos cognitivos das sociedades no passado é demonstrada em diversos casos; a interpretação das descobertas de Phylakopi como santuário micênico é um exemplo disso. Nas evidências arqueológicas se encontra incorporado o esquema intelectual que governa as ações humanas; para compreendê-lo é necessário desenvolver procedimentos explícitos, um corpo teórico coerente, por meio dos quais aplicar a abordagem da arqueologia dos sistemas à análise cognitiva, que deve tornar-se parte da reflexão sobre a mudança sociocultural.

Esse programa encontra uma primeira formulação em Archeology of Cult [Arqueologia do Culto] (1985a): Renfrew constrói uma estrutura de inferência para elaborar, com base na evidência arqueológica, hipóteses sobre as práticas de culto e sobre as crenças religiosas do passado. Dentre as representações de caráter simbólico que constituem a maior parte dos testemunhos disponível ao arqueólogo, ele discute essas características: 1) a relação entre o simbólico e seu significado frequentemente torna-se convencional e é usada regularmente e repetitivamente da mesma forma; 2) os símbolos frequentemente encontram-se usados no mesmo contexto: estabelecido com segurança o contexto, uma associação de símbolos mantém provavelmente o mesmo significado em 
um contexto equivalente; 3) frequentemente a forma dos símbolos não é arbitrária, mas é ligada graficamente ao conceito representado: intrinsicamente, ou por metonímia, ou através de outras relações. Além disso, identifica uma série de correlatos arqueológicos da situação cultural gerada pela estrutura do sistema do ritual sacro, que o arqueólogo pode esperar discernir nas evidências arqueológicas, por exemplo, a utilização de meios específicos para focalizar a atenção (um altar). Renfrew se propõe a articular exaustivamente em uma lista de 18 pontos os correlatos arqueológicos e declara que essas características oferecem a possibilidade de reconhecer um santuário enquanto tal sobre base puramente arqueológica.

Reconhece-se na concepção de "estrutura de inferência" proposta por Renfrew a ideia de "modelo" que caracteriza explicitamente os seus trabalhos dos anos precedentes. Alguns dos problemas são os mesmos (como desenvolver um modelo que valha em diversos contextos culturais?), ou melhor, eles são talvez ainda mais delicados no campo da religião. Certas contradições inerentes a essa abordagem vêm à luz no trabalho mesmo sobre Phylakopi. As descobertas, de fato, fazem considerar plausível que se trata de um santuário, mas não existem provas decisivas se os critérios formulados são aplicados. Para identificar os restos de Phylakopi como um santuário é necessário levar em consideração evidências provenientes de outros sítios do Egeu, com o risco de que a argumentação se torne viciosa; por outro lado, esse discurso vale para qualquer sítio pré-histórico do Egeu. Trata-se de um problema epistemológico: as observações provenientes de um número de sítios diversos são necessárias para estabelecer a validade de uma hipótese que não pode ser colocada à prova com relação a nenhum sítio examinado sozinho. Renfrew propõe uma solução baseandose no conceito de interação entre comunidades paritárias: nos vários assentamentos do Egeu se encontra recorrentemente um determinado sistema de símbolos e é nesse contexto mais amplo de interação da expressão simbólica que se devem interpretar as descobertas de Phylakopi. Os vários sítios, considerados como um todo, satisfazem mais adequadamente os critérios estabelecidos. 0 caso de Phylakopi é revelador de alguns dos problemas da generalização como é compreendida por Renfrew: qual é a validade de uma estrutura de inferência e valor geral com relação aos únicos contextos culturais?

O conceito de interação entre comunidades paritárias ocupa um papel central também na tentativa ambiciosa de Renfrew de criar um modelo para a integração da dimensão cognitiva nos processos de mudança sociocultural (1987b). Trata-se da comunicação apresentada em uma conferência interdisciplinar dedicada à modelização de sistemas complexos e inspirada nas novas teorias da física como a dinâmica não linear, o caos determinístico, as estruturaras dissipadoras etc. Mede-se novamente aqui a abertura para as disciplinas científicas por parte de Renfrew, mas também a dificuldade de aplicação de certos modelos nas ciências sociais e talvez a defasagem no diálogo entre as ciências humans e naturais, no momento no qual aquelas naturais mudaram profundamente e aquelas humanas encontram-se a recorrer a noções então superadas no campo científico. Renfrew propõe um modelo para simular o comportamento humano: cada indivíduo se orienta no mundo usando o próprio "mapa mental"; agregados de indivíduos compartilham um mapa mental que representa o caráter cultural do grupo. O desenvolvimento da complexidade 
sociocultural deriva na maior parte do tempo dos casos de uma intensificação da produção, que é governado, seja voluntária ou coercitivamente, por mecanismos de natureza simbólica colocados em ação nas interações entre comunidades paritárias que vem a compartilhar assim um sistema de símbolos, ou seja, um mapa cognitivo.

\subsection{A arqueologia da mente como arqueologia cognitiva}

A reflexão de Renfrew sobre o aspecto cognitivo e simbólico da atividade humana e o desenvolvimento da discussão sobre a "arqueologia da mente" estão compreendidos dentro do debate teórico em curso na arqueologia naqueles anos. Desde o início dos anos oitenta se afirmam na cena britânica vozes novas: uma nova geração de jovens arqueólogos, através de uma crítica aprofundada da Nova Arqueologia, constrói uma metodologia definida simbólico-estrutural, ou pósprocessual.

No debate em torno das propostas de Michael Shanks e Chris Tilley e de suas críticas à arqueologia processual devido a seu naturalismo, cientificismo, fenomenalidade e empirismo (SHANKS; TILLEY, 1987a; 1987b), intervém, além de Renfrew (1989a), também lan Hodder (1989), o canadense Bruce Trigger (1989a) e os próprios Shanks e Tilley (1989). Segundo estes últimos, o erro da Nova Arqueologia é o de ter procurado reduzir a história a uma série de processos, de generalizações ahistóricas; ao invés disso, é necessário levar seriamente em consideração as ideias de história e de descontinuidade e, dentro dessas, dar espaço ao papel desempenhado pela ação intencional do indivíduo. Essa concepção vem acompanhada da ideia de um passado pluralista e polissêmico cuja reconstrução depende da contribuição de diversos 'discursos' arqueológicos.

Hodder critica algumas rigidezes da posição de Shanks e Tilley: sublinha que a Nova Arqueologia tentou incorporar algumas ideias pós-processuais: um exemplo é o próprio Renfrew, que no curso dos anos oitenta demonstrou reserva no uso de modelos de otimizações simplistas e, em vez disso, interessou-se pela adoção de análises das estruturas e da ideia de redes de significados e de comunicação e na importância da história (1982b; 1986a).

A participação no debate de Trigger, estudioso da geração de Renfrew, é significativa porque ele criticou a Nova Arqueologia desde o início dos anos setenta; as origens da abordagem simbólico-cultural podem ser traças em sua obra (GUIDI, 1988, p. 231). Trigger não considera prática a alternativa proposta por Shanks e Tilley, marcada pelo idealismo histórico-culturalista e pelo relativismo; somente através de uma abordagem diretamente histórica é possível recuperar os significados particulares atribuídos por culturas pré-históricas específicas em suas formas de representação simbólica.

Nessa discussão Renfrew é o defensor da arqueologia processual. Antes de tudo ele refuta a definição de arqueologia "pós-processual", que prefere definir "anti-processual". A arqueologia antiprocessual carece de qualquer concepção coerente da prática da pesquisa arqueológica enquanto disciplina sistemática; além disso, propõe uma ideia da cultura material como "texto" que abre a via para a possibilidade de reconstrução arbitrária do passado privada de qualquer base científica. Cita o 
seu primeiro artigo (1962), no qual ainda estudante tinha discutido a posição de "correspondência" entre uma teoria e os dados e aquela de "coerência" de uma teoria com as teorias da tradição: a fraqueza de Shanks e Tilley é a sua proximidade com a posição de "coerência". Aceita algumas críticas: por exemplo, a carência da primeira geração da Nova Arqueologia com relação às temáticas cognitivas e simbólicas da cultura humana. Porém, a arqueologia processual já se movimentou de uma fase "funcional-processual" para uma fase "cognitivo-processual". Algumas das características desta respondem à exigência colocada pela arqueologia anti-processual: o reconhecimento de que o estudo dos acontecimentos humanos requer fundamentos teóricos além daqueles necessários ao estudo das ciências naturais; a recusa de uma posição de positivismo extremo; o reconhecimento do papel criativo e subjetivo do pesquisador ao formular hipóteses, teorias, explicações; a recusa do método de Hempel; a dificuldade da potencial viciosidade dos conceitos evolucionistas de "adaptação". A arqueologia cognitiva, todavia, sublinha Renfrew, continua a tradição da arqueologia processual mantendo a metodologia científica rigorosa da formulação explícita de uma hipótese da qual se deduzem as consequências lógicas para colocá-la à prova no confronto com os dados ${ }^{21}$.

Um outro episódio do debate geracional que provocou uma resposta atenta de Renfrew foi o acolhimento com reservas de seu livro sobre as estatuetas cicládicas (1991c). É após certas resenhas (Broodbrank 1992) que se explica o empenho de Renfrew confrontar, em modo explicitamente militante, o tema do colecionismo e dos furtos de arte (1993c; 1995b; 1995d).

Para a arqueologia cognitiva é dedicado um número da revista "Cambridge Archaeological Journal", que reúne as contribuições de diversos autores sob o título de Cognitive Archeology: Some Thoughts on the Archaeology of Thought [Arqueologia Cognitiva: Algumas Reflexões sobre a Arqueologia do Pensamento]. No debate, do qual Renfrew (1993d) e Hodder (1993) representam os dois pólos, se colhe bem a diferença entre as concepções dos dois estudiosos, não apenas sobre a teoria e a metodologia da arqueologia cognitiva, mas também sobre qual seria seu objeto de investigação. Renfrew instaura uma correspondência entre simbólico e cognitivo e identifica as mais importantes categorias de uso dos símbolos: o desenho, o planejamento, a mensuração, as relações sociais, o sobrenatural, a representação. Hodder sublinha que o processo cognitivo pode explicarse somente em uma perspectiva social e identifica nela três tipos: aquele que funciona sobre o modelo lingüístico (a linguagem, verbal e escrita, e o simbolismo material); aquele envolvido no conhecimento de tipo prático; aquele que diz respeito ao modo pelo qual os próprios arqueólogos organizam o conhecimento. A discussão sobre a arqueologia cognitiva nesses anos tende a se fechar a tal ponto em torno de Cambridge que, aos olhos de muitos observadores externos, a posição de Hodder e Renfrew, embora profundamente diversas, quase se confundem ${ }^{22}$.

A amplitude do debate teórico sempre mais áspero desenvolvido com a Nova Arqueologia

\footnotetext{
21 Renfrew continuou a ocupar-se da definição da arqueologia cognitiva-processual em alguns trabalhos dos anos sucessivos; no manual de grande sucesso escrito com Paul Bahn (RENFREW, 1991b) ela é definitiva, na seção dedicada aos diversos tipos de explicações em arqueologia, a "nova síntese"; um tratamento mais complexo dessa abordagem se encontra em The Ancient Mind [A Mente Antiga], que reúne as atas de uma conferência por ele organizado em 1990 (RENFREW, 1994a).
}

22 Veja por exemplo, LAMBERG-KARLOVSKJ, 1989, p. 7. 
vem acompanhada de um interesse crescente pela história da disciplina. Por um lado, a arqueologia processual frequentemente acompanhou o seus projetos e intervenções polêmicas com discussões de história da arqueologia (1974e e 1982e). Por outro lado, certas críticas à Nova Arqueologia sublinharam os aspectos de continuidade com a tradição precedente (TRIGGER, 1989a; CAZZELLA, 1985). Os pós-processualistas rescreveram, em vez disso, uma história da teoria arqueológica cujos protagonistas são Clarke e Childe. Childe em particular oferece um exemplo de uma figura sobre a qual foi exercida a fundo a investigação histórica e sobre a qual foram dedicadas leituras muito diversas ${ }^{23}$. Trigger já em 1989 publica um estudo das obras de Childe no qual fornece uma leitura complexa das suas reflexões e de sua variação ao longo do tempo, de modo a anular por um lado as críticas de Renfrew e dos outros processualistas, e por outro identificar propriamente no pensamento de Childe os elementos para superar os próprios limites da Nova Arqueologia (TRIGGER, 1980). Renfrew, em vez disso, traça uma história da arqueologia em que Childe é um predecessor da arqueologia processual e os pós-processualistas fazem parte da arqueologia processual sem se darem conta (1994i).

\subsection{Arqueologia e linguagem}

Archaeology and Language: the Puzzle of Indo-European Origins [Arqueologia e Linguagem: o Quebra-Cabeças das Origens Indo-Europeias] (1987a), segundo Renfrew uma revisitação crítica (review) do problema indo-europeu, deu origem a novas polêmicas.

O livro introduz como novo campo de pesquisa na obra de Renfrew esse problema tradicional da pré-história europeia. Paralelamente a uma linguística indo-europeia foi desenvolvida uma arqueologia indo-europeia com o intuito de identificar a partir dos achados arqueológicos o povo indo-europeu e seus movimentos. Childe dedicou ao problema indo-europeu dois livros (1926 e 1950): no primeiro, situava a pátria dos indo-europeus nas estepes da Rússia meridional, no segundo, tendia a privilegiar uma origem anatólia ${ }^{24}$. A teoria da origem indo-europeia das estepes foi argumentada recentemente de modo mais convincente por Marija Gimbutas, que conecta a difusão das línguas indo-europeias a várias ondas migratórias, verificadas entre 4000 e 2500 a.C. ${ }^{25}$ : nelas são protagonistas o povo da cultura dos Kurgan, aquele dos copos campaniformes e aquele dos campos de urnas. Essa visão produz uma narrativa sugestiva e complexa da pré-história europeia: a cultura indo-europeia originada nas estepes, teria se imposto, através de invasões violentas, sobre a cultura neolítica europeia precedente, pacífica e dedicada à agricultura, aos ritos de fertilidade e ao culto da deusa-mãe ${ }^{26}$.

\footnotetext{
23 Além de Trigger e Renfrew citados, veja GREEN, 1981; SHERRATT, 1989; HARRIS, 1994; TRIGGER, 1994.

24 Childe era por formação estudioso de letras clássicas; a sua tese de graduação em Oxford tratava dos indo-arianos; torna-se em seguida arqueólogo para procurar uma solução para esses problemas.

25 Mais precisamente três ondas migratórias entre 4400-4300, 3500 e 3000-2800 a.C. (N.T.)

26 Sobre a cultura da deusa-mãe pré-indo-europeia Gimbutas escreveu o seu último livro (1989), que contem toda sua bibliografia sobre o problema indo-europeu. [The Language of the Goddess [A Linguagem da Deusa] não é o último livro de Gimbutas concluído em vida, e sim The Civilization of the Goddess [A Civilização da Deusa] (1991), que apresenta uma visão panorâmica da organização social e religiosa das sociedades neolíticas europeias antes das
} 
A reflexão de Renfrew sobre o problema indo-europeu e das relações entre arqueologia e linguagem é reveladora das ligações contraditórias que ele mantém com aquela que define arqueologia tradicional. É possível reconstruir a história dessa reflexão, desde o exame de alguns problemas que dizem respeito à pré-história do Egeu até a uma consideração da difusão das línguas que envolvem a abordagem arqueológica processual e as últimas descobertas da genética.

\subsection{Pré-história das línguas do Egeu}

Em um artigo precedente à tese de doutorado (1964b), o jovem estudioso propunha uma crítica da teoria dominante que via uma primeira migração no início da Idade do Bronze, responsável pela introdução de uma língua pré-grega, e uma na metade da Idade do Bronze, portadora do grego indo-europeu ${ }^{27}$. A continuidade das evidências pré-históricas cretenses - tema fundamental na dissertação (1965a) - contradiz uma migração no início da Idade do Bronze. A única possibilidade oferecida pelas evidências arqueológicas para supor que houvera uma incursão relevante do exterior era, na opinião de Renfrew, o próprio início do Neolítico com a introdução da agricultura: a invasão pré-grega se põe muito mais provavelmente no VII milênio a.C. do que no III milênio a.C., aquela das populações de língua grega é arqueologicamente discutível. Renfrew concluía o artigo escrevendo:

Pode ser que os gregos não vieram de lugar algum, que, nas palavras de Sir John Myres, eles estivessem "sempre no processo de se tornar". Talvez, portanto, os habitantes de Creta e das Cíclades no tempo anterior a Rhadamanthus falassem uma linguagem, o ancestral direto precursor do grego. (1964b, p. 131) ${ }^{28}$.

Sobre a dimensão grega do problema indo-europeu deve ser lembrada a posição de Moses Finley, um ponto de vista mais do que nunca aberto sobre a intricada questão. Ele achava difícil negar a evidência de uma profunda fratura na documentação arqueológica entre o Heládico II e Heládico III, por volta de 2200 ou 2100 a.C.:

O "advento dos gregos", em outras palavras, representou a chegada de um elemento novo que, combinando-se com seus predecessores, criou lentamente uma civilização nova, expandindo-a como e até onde foi possível (FINLEY 1970, trad. pt. 1990, p. 19).

Na comunicação da conferência Bronze Age Migrations in the Aegean [Migrações no Egeu da Idade do Bronze] (1973d) Renfrew reafirma que as evidências arqueológicas não provam absolutamente uma introdução cultural na Grécia durante a Idade do Bronze e propõe, portanto,

invasões indo-europeias (a Velha Europa, de acordo com o termo cunhado pela estudiosa). Gimbutas, antes de sua morte, concluía uma revisão de uma antologia de artigos sobre sua hipótese indo-europeia, The Kurgan Culture and the Indo-Europeanization of Europe [A Cultura Kurgan e a Indo-europeirização da Europa] (1997), bem como a escrita de um último livro sobre a ideologia religiosa pré-indo-europeia, The Living Goddesses [As Deusas Vivas] (1997), postumamente editados e publicados. Assim, portanto, acredito que a indicação de Ceserani não ser tão precisa para o tema que ela quer endereçar o leitor, dado que o escopo de The Language of the Goddess ser os códigos pictóricos da religião da Velha Europa (N.T.)].

27 Essa solução ao aspecto grego do problema indo-europeu se encontra no livro de Childe citado; para ela foi fundamental BLEGEN, 1928.

$28 \quad$ Na realidade o trecho citado encontra-se na página 141 (N. T.). 
uma cronologia muito mais longa para as mudanças linguísticas na área do Egeu. O pressuposto para esse tipo de discussão é a nova abordagem processual. Estes os postulados fundamentais da sua teoria: 1) o grego se desenvolveu na Grécia de uma língua mais antiga, parte do continuum linguístico indo-europeu extendido na Europa antes da Idade do Bronze Egeia Antiga; 2) essa língua indo-europeia antiga era falada na Grécia antes do início da Idade do Bronze; 3) os sufixos dos topônimos chamados pré-gregos foram conservados como fósseis dessa linguagem postulada, antepassado direto do grego. Destes postulados Renfrew deriva um quarto, de natureza hipotética: as línguas indo-europeias, antepassados das europeias, teriam sido levadas pelos primeiros agricultores advindos da Anatólia; a sua difusão na Europa teria seguido o esquema da difusão da agricultura.

\subsection{O quebra-cabeças do indo-europeu}

Em Archaeology and Language, colocando no centro da investigação o problema indoeuropeu em sua complexidade, Renfrew desenvolve o quarto postulado do artigo de 1973. A origem do indo-europeu deve ser procurada nas origens da agricultura; na realidade, no sudeste da Anatólia em 7000 a.C., um dos três lóbulos da zona nuclear da agricultura, originou-se a forma arcaica do indo-europeu. Trata-se de uma hipótese interessante, ele sustenta, porque arqueologicamente de simples evidência: os agricultores têm as cerâmicas, os caçadores-coletores não.

Renfrew analisa a mudança linguística segundo o método processual e, portanto, sob a forma de generalização. Os processos possíveis são três: 1) a colonização inicial de um território antes desabitado; 2) a substituição linguística; 3) o desenvolvimento contínuo de uma língua que muda no tempo pelos diversos fatores de estabilidade, inovação, divergência e convergência. Para o fenômeno da substituição linguística, Renfrew propõe três modelos: I) demografia/subsistência: desenvolvida uma nova técnica, um grande número de falantes se move em direção a um novo território, provocando um incremento demográfico; II) predomínio de uma élite: a chegada de um exíguo grupo fortemente organizado de língua diversa que submete por superioridade material a população local; III) colapso de um sistema, verossímil na antiguidade quando as sociedade estatais eram muito instáveis.

Para sua interpretação da dispersão das línguas indo-européias na Europa sobre a base do modelo demografia/subsistência ligado ao fenômeno da difusão da agricultura, Renfrew retorna ao modelo matemático de "onda de avanço" elaborado por A. J. Ammermann e L. L. Cavalli-Sforza (1973; 1979) e confirmado pelas estatísticas sobre a genética das populações. Seguindo o percurso inverso de uma semente nas colheitas de ano em ano, de geração em geração, se pode traçar uma linha que atravessa a Europa e das Órcades, onde alcança em 3500 a.C., e que conduz ao Neolítico grego, em torno de 6000 a.C.; segundo Renfrew é possível fazer o mesmo percurso para a genealogia dos humanos e, portanto, para a língua dos agricultores. A “onda de avanço" deve ser considerada assim como uma série contínua de transformações nas quais a população agrícola tem um papel ativo: para dar conta da complexidade do quadro, ele precisa acrescentar em certos casos a obra de 
mudanças sob o modelo do predomínio de élite; as sobrevivências de línguas não indo-europeias são atribuídas a grupos mesolíticos de economia florescente, ou que adotaram eles mesmos as técnicas agrícolas. Renfrew deriva disso a hipótese de uma série de novas transformações que teriam originado a dispersão das línguas arcaicas europeias como nós as conhecemos.

A nova teoria conturba também a mitologia indo-europeia comparada. O compartilhamento de instituições sociais identificada pelos estudos de Dumézil, como a estrutura social tripartida, são, segundo Renfrew, o resultado de coincidências ou de desenvolvimentos paralelos. Na sua revisão do problema do indo-europeu, Renfrew põe em prática todas as ferramentas por ele elaboradas no curso dos anos: a ideia de processo cultural, a aplicação dos modelos de mudança cultural, a utilização das contribuições das ciências naturais (a "onda de avanço" como modelo para a difusão da agricultura), a centralidade do modelo de chefia. Impressiona que este aparato instrumental seja utilizado para procurar a resposta a uma pergunta formulada nos termos do século passado. Além disso, aparece aqui de modo evidente um dos riscos de sua concepção dos modelos: a arbitrariedade de um modo de proceder que, através da transposição - conduzida de um modo bastante abstrato e apririorístico, - dos modelos de mudança cultural no campo da linguística, constitui duas classes de fenômenos como comparáveis e considera a relação, arbitrariamente instituída, prova que corrobora a tese interpretativa.

A revista "Current Anthropology" publicou uma crítica-debate sobre Archaeology and Language. Grame Barker (1988), especialista das origens da agricultura ba Europa, critica o modelo da onda de avanço por sua simplicidade enganadora. Segundo Marija Gimbutas (1988), a visão de Renfrew, simplista e migracionista, representa uma aberração, que excede qualquer possibilidade de crítica racional, da pré-história europeia e asiática como se conhece através das investigações científicas da história, da mitologia comparada, da linguística e da arqueologia. Andrew Sherratt (1988) propõe, ao invés disso, tornar mais complexa a visão de Renfrew conjecturando um desenvolvimento em três fases para a difusão da agricultura e das línguas indo-europeias, sublinhando o papel desempenhado também pela difusão secundária de técnicas avançadas de agricultura e criação e ainda sucessivamente da nova expansão ligada a fatores econômicos no Bronze Tardio. Tal conceito, colocando em jogo também o conceito de língua franca das trocas comerciais, neutralizaria, por exemplo, a dificuldade, inevitável na teoria de Renfrew, derivada da ideia, linguisticamente difícil de aceitar, qua a maior parte das línguas indo-europeias descendem de um suposto proto-grego.

\subsection{Modelos de mudança linguística}

Falando para um público de linguistas, Renfrew (1989b) estendeu o modelo elaborado para o indo-europeu até uma reconstrução da difusão das línguas em nível mundial. Da pesquisa dos anos oitenta acolhe três hipóteses: 1) na Europa, as capacidades linguísticas associadas ao homem moderno aparecem 40,000 anos atrás; 2) a espécie do homem homo sapiens sapiens alcança a Europa 35,000 anos atrás; 3) existem macro-família que abrangem todas as línguas do globo. Agora é possível 
reunir [essas vertentes] em uma linha de especulação. É apenas especulação, e como tal pode encontrar ceticismo justificado. Porém enquanto para o linguista histórico falar de longos períodos de milhares de anos é difícil e, portanto, freqüentemente imprudente, o arqueólogo pré-histórico não sofre de tais limitações.

Renfrew propõe um quadro monogenético: o homo sapiens sapiens teria difundido as primeiras línguas pertencentes ao nostrático (suposta macro-família que compreende o afroasiático, o indo-europeu, o dravídico, o urálico, o altaico e o cartevélico) nas migrações originárias do Pleistoceno da África em direção à Ásia, à Austrália e à América em ondas sucessivas, segundo o modelo de subsistência-demografia ligado à agricultura. As sucessivas substituições linguísticas teriam ocorrido novamente segundo o modelo da subsistência-agricultura, mas em associação com as inovações técnicas secundárias, enquanto substituições linguísticas mais tardias teriam seguido o modelo de élite dominante. Este é o primeiro artigo no qual Renfrew cita cautelosamente os resultados das pesquisas de genética.

As hipóteses de Renfrew, apesar de amplamente criticadas em ambiente linguístico, todavia conquistaram o seu lugar, ainda que como hipóteses contras as quais se confrontar. Contra elas, por exemplo, se expressou Francisco Villar, restabelecendo a identidade dos estudos de indo-europeu. E também o novo manual de linguística histórica e comparada de Hans Hock e Brian Joseph (1996) não pôde fazer menos que discuti-las. Em uma perspectiva mais ampla, Giulio Lepschy (1992, 1820) explica que nas hipóteses de Renfrew volta a ideia de uma origem monogenética do homem, depois de anos nos quais tinha prevalecido a ideia de uma origem poligenética, e vem diminuída a data do início da capacidade linguística do homem: da visão segundo a qual esta se perdia na aurora da história humana, centenas de milhões de anos atrás, ela vem reaproximada a 'apenas' 100.000 anos atrás, na Europa 40.000. Renfrew ampara a documentação arqueológica à interpretação que sobre ela vem apresentada nos estudos sobre os grupos sanguíneos e sobre frequências genéticas de Cavalli-Sforza e as hipóteses de classificações das línguas do mundo em macro-famílias de Joseph Greenberg (1966 e 1987) e Merritt Ruhlen (1987) ${ }^{29}$. É inevitável que tal reconstrução não satisfaça os estudiosos dos indo-europeus: Greenberg e Ruhlen construíram as suas macro-famílias sobre semelhanças tipologicamente muito diversas daquelas da tradição linguística comparativa indoeuropeia, fundada sobre rigorosa e precisas leis fonéticas.

\subsection{Modelos de mudança para a genética}

Renfrew (1992a) busca nos resultados da genética o teste científico das próprias teorias sobre arqueologia e linguagem: trata-se da aplicação de seu conceito de explicação que teve até agora o melhor exemplo a propósito das datas calibradas em radiocarbono e do desmantelamento do modelo difusionista (1970a; 1973a). O paralelo com o resultado do decaimento dos isótopos do radiocarbono recorda, no entanto, também o paralelo perdido: nos processos de evolução biológica

29 Na segunda edição de seu livro publicada em 1991 Ruhlen discute explicitamente a relação entre a sua pesquisa e aquela de Renfrew no capítulo entitulado Post-scripts on Recent Developments [Escritos Posteriores sobre os Recentes Desenvolvimentos]. 
e naqueles do desenvolvimento cultural humano não existe uma taxa constante; portanto, parece hipotético combinar a perspectiva taxonômica com aquela filogenética.

Renfrew está ciente desta dificuldade, mas assume uma posição otimista, mesmo que sobre a base das novas e mais refinadas técnicas de análise genética molecular capaz de confrontar estruturas em vez de sequências genéticas ${ }^{30}$. Em seguida, procede na definição de possíveis correlações entre os diversos tipos de mudança linguística e as eventuais mudanças do patrimônio genético, necessárias para as interpretações dos dados: 1) a colonização inicial comporta uma mudança de cem por cento do patrimônio genético; 2) o modelo da divergência linguística estreitou analogias com o fenômeno da deriva genética; 3) o modelo da convergência linguística estreitou analogias com o fenômeno do fluxo genético; 4) a substituição linguística abre diversas possibilidades de acordo com os modelos: I) demografia-subsistência: por exemplo o caso da difusão dêmica da "onda de avanço" de Ammermann e Cavalli-Sforza que comporta uma notável mudança da freqüência genética; II) o caso da língua franca que passa de secundária à primária provocando um ligeiro fluxo gênico; III) o modelo da élite dominante pode ser ulteriormente articulado: trata-se de um grupo exíguo, que pode ter, no entanto, um acesso preferencial ao matrimônio e assim obter um efeito numericamente desproporcional sobre a frequência genética; IV) o caso do colapso de uma sistema é símile àquele da élite dominante.

A abertura sugestiva da problemática linguística e arqueológica aos dados provenientes da análise da genética comporta problemas enormes. Dos mesmos dados Cavalli-Sforza elaborou uma teoria para a origem dos indo-europeus muito mais de acordo com aquela tradicional de Gimbutas (Cavalli-Sforza 1993, 161). Sobre as propostas de conciliar os dados da genética com uma interpretação histórico-linguística é interessante um artigo escrito por um estudioso de genética a fim de dialogar com os arqueólogos (Bateman 1990), muito pessimista sobre a possibilidade de tais operações. Além disso, parece novamente discutível o modo de proceder de Renfrew: aplica arbitrariamente os seus modelos de mudança ao desenvolvimento genético de modo a constituir uma terceira classe para combinar com aquela da mudança cultural e linguística e corroborar a tese proposta.

\section{CONCLUSÕES}

O percurso de Renfrew é pleno de desenvolvimentos. Como conclusão dessa exposição gostaria de citar alguns de seus recentes escritos sobre o tema da etnicidade e identidade (1993a; 1994g), palavras correntes na arqueologia anglo-saxã dos anos noventa, sobretudo de tipo pósprocessual.

Encarando o problema das "raízes da etnicidade", Renfrew (1993a) discute as origens daquelas que considera as diversidades humanas: genética, linguística e cultural (em arqueologia esta última é representada pela cultura material). Renfrew constrói uma explicação em nível global da dispersão das línguas e dos genes: de um único antepassado africano se chega à dispersão mundial dos homens

30 Um progresso em relação ao método usado por Ammermann e Cavalli-Sforza (1973; 1979). 
e das suas línguas. Revela-se aqui uma das contradições do princípio de validade generalizante dos modelos de Renfrew: se o valor generalizante significa por si a extensão da teoria das origens indoeuropeias aos outros casos do mundo, é, portanto, da possibilidade de aplicar o modelo em outros contextos que se passa à globalização do próprio modelo, onde está a possibilidade, evocada por Renfrew (1982a), de colocar à prova e de proceder à comparação?

No escrito dedicado à identidade da Europa (1994g), do problema da globalização se passa àquele da unicidade de cada continente. Trata-se do discurso proferido no primeiro encontro da recém-fundada European Association of Archaeologists [Associação de Arqueólogos Europeus]. A definição da unicidade da pré-história europeia é encontrada por Renfrew, após ter discutido ainda mais uma vez a definição dada por Childe ao fim de sua carreira (1958), na Europa bárbara da Idade do Bronze. É aqui que aparecem as características europeias únicas: nas sociedades de ranqueamento do I milênio a.C., de tipo chefia, que conheceram e desenvolveram por muito tempo a metalurgia do bronze e às vezes do ferro antes de se tornarem sociedades estatais. Segundo o estudioso estas comunidades desenvolvidas além dos confins do Império romano adquirem um significado central na história europeia; as sociedades emersas após o colapso do Império romano a elas devem muito mais, na sua estrutura social, do que à romanitas.

Childe identificava a origem da identidade europeia no encontro entre os prospectores provenientes do Oriente Próximo, portadores de inovações tecnológicas devido a milênios de regimes totalitários capazes de acumular capital cultural, e os habitantes da Grécia, beneficiários daquelas inovações em sociedade de tipo igualitário. Ao invés disso, Renfrew procura a sua Europa entre as sociedades de chefia do norte desenvolvidas em autonomia do Oriente Próximo - dominadas pelos big men - e na concepção de valor por elas elaborada em relação à difusão da metalurgia. A versão de Childe e de Renfrew, embora extremamente divergentes, atuam ambas na mesma ideia de narrativa da pré-história europeia. Trata-se de um dos aspectos de herança da arqueologia tradicional na obra de Renfrew. Isso surpreende ainda mais na medida em que os trabalhos sobre a etnicidade dos anos noventa percorrem vias e problemas em geral muito diversos ${ }^{31}$.

$\mathrm{Na}$ interpretação que Renfrew deu para a identidade da Europa pré-histórica se pode reconhecer o contributo de várias das linhas de desenvolvimento de seu percurso. Certamente não é casual que o papel predominante na definição da identidade europeia seja por ele atribuído às sociedades de chefia, caracterizadas por uma organização intermediária entre tribo e Estado, o principal objeto da sua investigação sobre a mudança cultural. Pode-se ver como na perseguição de um novo modo de estudar a arqueologia europeia ele tenha chegado a construir uma nova imagem da Europa e como esta seja produzida pela abordagem metodológica proposta. E talvez aqui se revela também um outro dos problemas dos modelos de Renfrew e da sua generalização: tendem a ser, apesar da sua cientificidade objetiva declarada, necessariamente eurocêntricos; Renfrew deixa aberta a possibilidade da sua aplicação a outras situações culturais.

Veja por exemplo os livros de Shennan (1989) e de Jones (1997). 


\section{OBRAS DE COLIN RENFREW ${ }^{32}$}

RENFREW, Andrew Colin. Comments on Dr. Daniel's Seminar on G. R. Lowther, "Epistemology and Archaeological Theory". Current Anthropology, v. 3, n. 5, p. 504, 1962.

.; CANN, Johnson Robin. The Characterization of Obsidian and its Application to the Mediterranean Region. Proceedings of the Prehistoric Society, v. 30, p 111-133, 1964a. . Crete and the Cyclades before Rhadamantus. Kretica Chronika, v. 18, p. 107-141, 1964b. .; BELMONT, John S. Two Prehistoric Sites on Mykonos. American Journal of Archaeology, v. 68, p. $395-400,1964 c$.

. Review of Archaeology and the Microscope. The Scientific Examination of Archaeological Evidence, by Leo Biek with a Foreword by Sir Mortimer Wheeler. London: Lutterworth Press 1963. 287 pp., 26 pls. (2 in colour). 45s. Antiquity, v. 38, n. 150, p. 153-154, 1964d. . The Neolithic and Early Bronze Age Cultures of the Cyclades and their external relations. Tese (Doutorado em Arqueologia). Universidade de Cambridge, Cambridge, UK. 1965a.

. CANN, Johnson Robin; DIXON, Jacqueline Eaby. Obsidian in the Aegean. Annual of the British School of Archaeology at Athens, v. 60, p. 225-247, 1965b.

.; DIXON, Jacqueline Eaby; CANN, Johnson Robin. Obsidian and Early Cultural Contact in the Near East. Proceedings of the Prehistoric Society, v. 32, n. 2, p. 30-72, 1966.

. Colonialism and Megalithismus. Antiquity, v. 41, n. 164, p. 276-288, 1967a.

. Cycladic Metallurgy and the Aegean Early Bronze Age. American Journal of Archaeology, v. 71 , n. 1, p. 1-20, 1967b.

.; DIXON, Jacqueline Eaby; CANN, Johnson Robin. Further Analysis of Near Eastern Obsidians. Proceedings of the Prehistoric Society, v. 34, p. 319-331, 1968a.

. Models in Prehistory. Antiquity, v. 42, n. 166, p. 132-134, 1968b.

. Wessex without Mycenae. Annual of the British School of Archaeology at Athens, v. 63, p. 277-285, 1968c.

.; EVANS, John Davies. Excavations at Saliagos near Antiparos. 1a ed, London: Thames \& Hudson, 1968d.

. Saliagos: a Neolithic Site in the Cyclades. Archaeology, v. 21, n. 4, p. 262-271, 1968 e.

. DIXON, Jacqueline Eaby; CANN, Johnson Robin. Obsidian and the Origins of Trade. Scientific American, CCXVIII, 38-46, $1968 f$.

. Greek Neolithic: Backward or Precocious? Current Archaeology, v. 1, n. 7, p. 168-172, 1968g.

. PEACEY, J. Springer. Aegean Marble: a Petrological Study. Annual of the British School of Archaeology at Athens, v. 63, n. 168, p. 45-66, 1968h.

32 Em muitas das obras escritas em co-autoria listadas nesta seção Renfrew não figura como primeiro autor. No entanto, optei por manter a organização bibliográfica da autora. As referências às traduções existentes em italiano foram eliminadas (N. T.). 
. Trade and Culture Process in European Prehistory. Current Anthropology, v. 10, n. 2-3, p. 151-169, 1969a.

; STERUD, Gene. Close-Proximity Analysis: a Rapid Method for the Ordering of Archaeological Materials. American Antiquity, v. 34, n. 3, p. 265-277, 1969b.

. The Autonomy of the South-East European Copper Age. Proceedings of the Prehistoric Society, v. 35, p. 12-47, 1969c.

. The Development and Chronology of the Early Cycladic Figurines. American Journal of Archaeology, v. 73, n. 1, p. 1-32, 1969d.

.; CANN, Johnson Robin; DIXON, Jacqueline Eaby. Obsidian Analysis and the Obsidian Trade. In: BROTHWELL, Don; HIGGS, Eric (Eds.). Science in Archaeology. 1a ed, London: Thames \& Hudson, 1969e, p. 578-591.

. The Arts of the First Farmers. 1a ed, Sheffield: Sheffield City Museum, $1969 f$.

. The Tree-ring Calibration of Radiocarbon: an Archaeological Evaluation. Proceedings of the Prehistoric Society, v. 36, p. 280-311, 1970a.

. New Configurations in Old World Archaeology. World Archaeology, v. 2, n. 2, p. 199211, $1970 b$.

.; SHACKLETON, Nicholas. Neolithic Trade Routes Realigned by Oxygen Isotope Analyses. Nature, v. 228, p. 1062-1065, 1970c.

.; NEWTON, R.G. British Faience Beads Reconsidered. Antiquity, v. 44, n. 175, p. 199-206, $1970 d$.

. Revolution in Prehistory. The Listener, v. 84, 807-900, 1970e.

. The Burnt House of Sitagroi. Antiquity, v. 34, n. 174, p. 131-134, $1970 f$.

. DURRANI, Saeed Akhtar; KHAN, Hafiz Atif; TAJ, M. Obsidian Source Identification by Fission Track Analysis. Nature, v. 233, p. 242-245, 1971a.

. Carbon 14 and the Prehistory of Europe. Scientific American, v. 225, p. 63-70, 1971b.

. Europe's Creative Barbarians. The Listener, v, 85, p. 12-14, 1971c.

. Sitagroi, Radiocarbon and the Prehistory of South-East Europe. Antiquity, v. 45, n. 180, p. 275-282, 1971d.

. The Meaning of the New Diggers. Encounter, v. 37, n. 4, p. 49-55, 1971e.

. The Place of the Vinča Culture in European Prehistory. Zbornic Naradnog Muzeja $u$ Beogradu, v. 6, p. 45-58, 1971 f.

. The Emergence of Civilisation: the Cyclades and the Aegean in the Third Millennium BC. 1a ed, London: Methuen, 1972a.

.; CLARK, R. Malcolm. A Statistical Approach to the Calibration of Floating Tree-ring Chronologies Using Radiocarbon Dates. Archaeometry, v. 14, n. 1, p. 5-19, 1972b.

.; ASPINALL, Arnold; FEATHER, Stuart Wharton. Neutron Activation Analysis of Aegean Obsidians. Nature, v. 237, p. 333-334, 1972c. 
. Malta and the Calibrated Radiocarbon Chronology. Antiquity, v. 46, n. 182, p. 141-144, $1972 d$.

- Patterns of Population Growth in the Prehistoric Aegean. In: UCKO, Peter John; TRINGHAM, Ruth; DIMBLEBY, Geoffrey William (Eds.). Man, Settlement and Urbanism. 1a ed, London: Duckworth, 1972e, p. 383-399.

. Prehistoric Trade. The Listener, v. 87, p. 104-106, $1972 \mathrm{f}$.

. Before Civilisation: the Radiocarbon Revolution and Prehistoric Europe. 1a ed, London: Jonathan Cape, 1973.

. (Ed.). The Explanation of Culture Change: Models in Prehistory. 1a ed, London: Duckworth, 1973b.

. Social Archaeology: an Inaugural Lecture Delivered at the University, 20th March 1973. 1a ed, Southampton: University of Southampton, 1973c.

. Problems in the General Correlation of Archaeological and Linguistic Strata in Prehistoric Greece: the Model of Autochthonous Origin. In: CROSSLAND, Ronald Arthur; BIRCHALL, Ann. (Eds.). Bronze Age Migration in the Aegean: Archaeological and Linguistic Problems in Greek Prehistory. 1a ed, London: Duckworth, 1973d.

. Monuments, Mobilization and Social Organization in Neolithic Wessex. In:

(Ed.). The Explanation of Culture Change: Models in Prehistory: Proceedings of a Meeting of the Research Seminar in Archaeology and Related Subjects Held at the University of Sheffield. 1a ed, London: Duckworth, 1973e, p. 539-558.

.; CLARK, R. Malcolm. Tree-ring Calibration of Radiocarbon Dates and the Chronology of Ancient Egypt. Nature, v. 143, p. 266-270, $1973 f$.

. Pour une archéologie sociale. Sciences et Avenir, v. 319, p. 886-910, 1973g.

. The Aegean and the Balkans at the Close of the Neolithic Period. In: CHROPOVSKÝ, Bohuslav (Ed.). Symposium über die Entstehung und Chronologie der Badener Kultur. $1^{\mathrm{a}}$ ed, Bratislava: Verlag der Slowatische Akademie der Wissenschaften, 1973h, p. 427-440.

. Trade and Craft Specialization in Neolithic Greece. In: THEOCHARIS, Demetrios. (Ed.). Neolithic Greece. 1a ed, Athens: National Bank of Greece, 1973i, p. 179-191.

. Beyond a Subsistence Economy: the Evolution of Social Organisation in Prehistoric Europe. In: MOORE, CharlotteB.(Ed.), Reconstructing Complex Societies: an Archaeological Colloquium. 1a ed, Cambridge, MA: Supplement to the Bulletin of the American Schools of Oriental Research n. 20, 1974a, p. 69-96.

.; WHITEHOUSE, Ruth. The Copper Age of Peninsular Italy and the Aegean. Annual of the British School of Archaeology at Athens, v. 69, p. 343-390, 1974b.

.; CLARK, R. Malcolm. Problems of the Radiocarbon Calendar and its Calibration. In: Archaeometry, v. 16, n. 1, p. 5-18, 1974c.

. Commerce et société pendant la Préhistoire. La Recherce, v. 5, p. 846-852, 1974d.

(Ed.). British Prehistory: a New Outline. 1a ed, London: Duckworth, 1974e. 
. Trade as an Action at Long Distance: Questions of Integration and Communication. In: SABLOFF, Jerry Arac; LAMBERG-KARLOVSKJ, Clifford Charles (Eds.), Ancient Civilization and Trade. 1a ed, Albuquerque: University of New Mexico Press, 1975a, p. 3-59.

Archaeology and the Earth Sciences. In: DAVIDSON, D.A.; SHACKLEY, M.L. (Eds.). Geoarchaeology. 1a ed, London: Duckworth, 1976a, p. 1-15.

.; HALLAM, B.R.; WARREN, S.E. Obsidian in the Western Mediterranean: Characterisation by Neutron Activation Analysis and Optical Emission Spectroscopy. Proceedings of the Prehistoric Society, v. 42, p. 85-110, 1976b.

.; DAVIDSON, Donald; TASKER, Catriona. Erosion and Prehistory in Melos: a Preliminary Note. Journal of Archaeological Science, v. 3, n. 3, p. 219-227, 1976c.

.; DAVIDSON, Donald; JONES, Robert. Palaeoenvironmental Reconstruction and Evaluation: a Case Study from Orkney. Transactions of the Institute of British Geographers, v. 1 , n. 3, p. 346-361, 1976d.

.; HARKNESS, Douglas; Switour, Roy. Quanterness, Radiocarbon and the Orkney Cairns. Antiquity, v. 50, n. 199-200, p. 194-204, 1976 e.

. Alternative Models for Exchange and Spatial Distribution. In: EARLE, Timothy K.; ERICSON, Jonathon (Eds.). Exchange Systems in Prehistory. 1a ed, New York: Academic Press, 1977a, p. 71-90.

. Ancient Europe is Older than We Thought. National Geographic Magazine, v. 152, n. 5 , p. $615-623,1977 \mathrm{~b}$.

.; DIXON, Jacqueline Eaby. Obsidian in Western Asia: a Review. In: SIEVEKING, Gale de Giberne; LONGWORTH, Ian, WILSON, K.E. (Eds.). Problems in Economic and Social Archaeology. 1a ed, London: Duckworth, 1977c, p. 137-150.

A Linear A Tablet Fragment from Phylakopi in Melos (with a note in the inscription by William C. Brice). Kadmos, v. 16, n. 2, p. 111-119, 1977d.

. Production and Exchange in Early State Society: the Evidence of Pottery. In: PEACOCK, David Philip Spencer (Ed.). Pottery and Early Commerce: Characterization and Trade in Roman and Later Ceramics. 1a ed, London: Academic Press, 1977e, p. 1-20.

. Retrospect and Prospect. In: in BINTLIFF, John (Ed.). Mycenaean Geography: Proceedings of the Cambridge Colloquium, September 1976. 1ㄹ ed, Cambridge, UK: British Association for Mycenaean Studies, 1977f, p. 108-109.

. The Cycladic Culture. In: THIMME, Jürgeb; GETZ-PREZIOSI, Pat (Ed.). Art and Culture of the Cyclades in the Third Millennium B.C. 1a ed, Chicago: University of Chicago Press, 1977g, p. 17-30.

. The Typology and Chronology of Cycladic Sculpture. In: THIMME, Jürgeb; GETZPREZIOSI, Pat (Ed.). Art and Culture of the Cyclades in the Third Millennium B.C. 1a ed, Chicago: University of Chicago Press, 1977h, p. 59-70.

. Time Depth in Orkney. Orb, v. 6, p. 51-58, 1977 i.

. The Later Obsidian of Deh Luran - The Evidence of Chagha Sefid. In: HOLE, Frank (Ed.). Studies in the Archaeological History of the Deh Luran Plain: The Excavation of Chagha 
Sefid. 1a ed, Ann Arbor: University of Michigan, 1977l, p. 238-311.

. The Mycenaean Sanctuary at Phylakopi. Antiquity, v. 52, n. 204, p. 7-15, 1978a.

. Dags att omvärdera folkvandringarna. Forskning och Framsteg, v. 8, p. 24-30, 1978b.

. Phylakopi and the Late Bronze I Period in the Cyclades. In: DOUMAS, Christos (Ed.). Thera and the Aegean World, Vol I. 1a ed, London; The Thera Foundation, 1978c, p. 403442.

. Space, Time and Polity, in FRIEDMAN, Jonathan; ROWLANDS, Michael John (Eds.). The Evolution of Social Systems: Proceedings of a Meeting of the Research Seminar in Archaeology and Related Subjects Held at the Institute of Archaeology. London University. 1a ed, London: Duckworth, 1978d, p. 89-114.

. The Anatomy of Innovation. In: GREEN, David; HASELGROVE, Colin; SPRIGGS, Matthew (Eds.), Social Organisation and Settlement, Oxford: British Archaeological Reports International, Supplementary Series, 47, 1978e, p. 89-117.

. To mykenaikon ieron tis Phylakopis. Eperetis tis Etaireias Kykladikon Meleton, v. 9, p. 767-795, $1978 f$.

. Trajectory, Discontinuity and Morphogenesis: the Implications of Catastrophe Theory for Archaeologists. American Antiquity, v. 43, n. 2, p. 203-222, 1978g.

. Varna and the Social Contexts of Early Metallurgy. Antiquity, v. 52, n. 206, p. 199-203, 1978h.

. Islands out of Time. In: SUTCLIFFE, Ray (Ed.). Chronicle: Essays from Ten Years of Television Archaeology. 1a ed, London: British Broadcasting Corporation, 1978i, p. 113126.

. Problems in European Prehistory. 1a ed, Edinburgh: Edinburgh University Press, 1979a.

.; COOKE, Kenneth (Eds.). Transformations: Mathematical Approaches to Culture Change. 1a ed, New York: Academic Press, 1979b.

. Systems Collapse as Social Transformation - Catastrophe and Anastrophe in Early State Societies. In: COOKE, Kenneth (Eds.). Transformations: Mathematical Approaches to Culture Change. 1a ed, New York: Academic Press, 1979c, p. 481-506.

.; POSTON, Tim. Discontinuities in the Endogenous Change of Settlement Pattern. In: COOKE, Kenneth (Eds.). Transformations: Mathematical Approaches to Culture Change. 1a ed, New York: Academic Press, 1979d, p. 437-462.

.; LEVEL, Eric. Exploring Dominance: Predicting Polities from Centers. In: COOKE, Kenneth (Eds.). Transformations: Mathematical Approaches to Culture Change. 1a ed, New York: Academic Press, 1979e, p. 145-168.

. Dialogues of the Deaf. In: BURNHAM, Barry; KINGSBURRY John (Eds.). Space, Hierarchy and Society: Interdisciplinary Studies in Social Area Analysis. 1a ed, Oxford: British Archaeological Reports International Series 59, 1979f, p. 253-259.

. Investigations in Orkney. 1a ed, London: The Society of Antiquaries of London, 1979g 
. Terminology and Beyond. In: DAVIES, Jack; CHERRY, John (Eds.). Papers in Cycladic Prehistory. 1a ed, Los Angeles: UCLA Institute of Archaeology, 1979h, p. 51-63.

. The Eruption of Thera and Minoan Crete. In: SHEETS, Payson; GRAYSON, Donald (Eds.). Volcanic Activity and Human Ecology. 1a ed, New York: Academic Press, 1979i, p. 565586.

. Ancient Bulgaria's Golden Treasures. National Geographic Magazine, v. 158, n. 1, p. 112-129, 1980a.

. The Great Tradition versus the Great Divide: Archaeology as Anthropology? American Journal of Archaeology, v. 84, n. 3, p. 287-298, 1980 b.

. Towards a Definition of Context: the North German Megaliths. Nachrichten aus Niedersachen Urgeschichte, v. 49, p. 3-20, 1980c.

. Questions of Minoan and Mycenaean Cult. In: HÄGG, Robin; MARINATOS, Nanno (Eds.). Sanctuaries and Cults in the Aegean Bronze Age: Proceedings of the First International Symposium at the Swedish Institute in Athens, 12-13 May, 1980. 1a ed, Stockholm: Svenska institutet i Athen, 1981a, p. 27-33.

. The Sanctuary at Philakopi. In: HÄGG, Robin; MARINATOS, Nanno (Eds.). Sanctuaries and Cults in the Aegean Bronze Age: Proceedings of the First International Symposium at the Swedish Institute in Athens, 12-13 May, 1980. 1a ed, Stockholm: Svenska institutet i Athen, 1981b, p. 67-79.

. The Simulator as Demiurge. In: SABLOFF, Jeryy Arac (Ed.). Simulations in Archaeology. 1a ed, Albuquerque: University of New Mexico Press, 1981c, p. 283-305.

.; EVANS, John Davies; CUNLIFFE, Barry Windsor (Eds.). Antiquity and Man: Essays in Honor of Glyn Daniel. 1a ed, London: Thames \& Hudson, 1981d.

; ROWLANDS, Michael John; B. ABBOTT SEGRAVES, Barbara (Eds.). Theory and Explanation in Archaeology: The Southampton Conference. 1a ed, New York: Academic Press, 1982a.

.; WAGSTAFF, John Malcolm (Eds.). An Island Polity: the Archaeology of Exploitation in Melos. 1a ed, Cambridge, UK: Cambridge University Press, 1982b.

. Explanation Revisited. In: .; WAGSTAFF, John Malcolm (Eds.). An Island Polity: the Archaeology of Exploitation in Melos. 1a ed, Cambridge, UK: Cambridge University Press, 1982c, p. 5-24.

Polity and Power: Interaction, Intensification and Exploitation. In: WAGSTAFF, John Malcolm (Eds.). An Island Polity: the Archaeology of Exploitation in Melos. 1a ed, Cambridge, UK: Cambridge University Press, 1982d, p. 264-290.

. Towards an Archaeology of Mind: an Inaugural Lecture Delivered Before the University of Cambridge on 30th November 1982. 1a ed, Cambridge, UK: Cambridge University Press, 1982e.

.; SHENNAN, Stephen (Eds.). Ranking, Resource and Exchange: Aspect of the Archaeology of Early European Society. 1a ed, Cambridge, UK: Cambridge University Press, $1982 \mathrm{f}$. 
Divided We Stand: Aspects of Archaeology and Information. American Antiquity, v. 48, n. 1, p. 3-16, 1983a.

. Geography, Archaeology and Environment 1: Archaeology. Geographical Journal, v. 149 , p. 316-323, 1983b.

. Introduction: The Cycladic World and its Art. In: DOUMAS, Christos. Cycladic Art, the N. P. Goulandris Collection. 1a ed, London: British Museum Publications, 1983c, p. 24-30.

. (Ed.). The Megalithic Monuments of Western Europe. 1a ed, London: Thames \& Hudson, 1983d.

. The Social Archaeology of Megalithic Monuments. Scientific American, v. 249, n. 5, p. 128-136, 1983e.

. Approaches to Social Archaeology. 1ạ ed, Edinburgh: Edinburgh University Press, 1984a.

. From Pelos to Syros: Kapros Grave D. and the Kampos Group. In: MACGILLIVRAY, Joseph Alexander; BARBER, R.L.N. (Eds.). The Prehistoric Cyclades: Contributions to a Workshop on Cycladic Chronology. 1a ed, Edinburgh: University of Edinburg, Department of Classical Archaeology, 1984b, p. 41-54.

. Speculations on the Use of Early Cycladic Sculpture. In: FITTON, Josephine Lesley (Ed.). Cycladica: Studies in Memory of N. P. Goulandris: Proceedings of the Seventh British Museum Classical Colloquium, June 1983. 1a ed, London: British Museum Press, 1984c, p. 24-30.

. The Archaeology of Cult: The Sanctuary at Phylakopi. 1a ed, London: The British School of Archaeology at Athens, 1985a.

- Archaeology and the Indo-European Languages - an Unresolved Problem. Paper delivered at the Fiftieth Anniversary Conference of the Prehistoric Society, Norwich, 30 March 1985, 1985b.

. (Ed.), The Prehistory of Orkney. 1a ed, Edinburgh: Edinburgh University Press, 1985c.

.; CHERRY, John (Eds.). Peer Polity Interaction and Social-Political Change. 1a ed, Cambridge, UK: Cambridge University Press, 1986a.

. Introduction. In: .; CHERRY, John (Eds.). Peer Polity Interaction and Social-

Political Change. 1a ed, Cambridge, UK: Cambridge University Press, 1986b, p. 1-18.

. A Neolithic Head from the Cyclades. Antiquity, v. 60, n. 229, p. 134-135, 1986c.

. A New Cycladic Sculpture. Antiquity, v. 60, n. 229, p. 132-134, 1986d.

.; GIMBUTAS, Marija; ELSTER, Ernestine (Eds.). Excavations at Sitagroi: a Prehistoric Village in Northeast Greece: Volume I. 1a ed, Los Angeles: UCLA Institute of Archaeology, 1986e.

. Interazione tra comunità paritarie e formazione dello stato. Dialoghi di Archeologia, v. 3, n. 4, p. 27-33, $1986 f$.

. Varna and the Emergence of Wealth in Prehistoric Europe. In: APPADURAI, Arjun (Ed.). The Social Life of Things: Commodities in a Cultural Perspective. 1a ed, Cambridge, UK: 
Cambridge University Press, 1986g, p. 141-168.

. The Prehistoric Maltese Achievement and its Interpretation. In: BONANNO, Anthony (Ed.), Archaeology and Fertility Cult in the Ancient Mediterranean: First International Conference on Archaeology of the Ancient Mediterranean. University of Malta, 25 September 1985. 1a ed, Amsterdam: John Benjamins Publishing, 1986h, p. 118-130.

. Archaeology and Language: the Puzzle of Indo-European Origins. 1a ed, London: Jonathan Cape, 1987a.

. Problems in the Modelling of Socio-cultural Systems. European Journal of Operational Research, v. 30, n. 2, p. 179-192, 1987b.

. Archaeology and Language. Current Anthropology, v. 29, n. 3, p. 437-441, 1988a.

.; DANIEL, Glyn. The Idea of Prehistory. 2a ed, Edinburgh: Edinburg University Press, $1988 \mathrm{~b}$.

. The Minoan-Mycenaean Origins of the Panhellenic Games. In: RASCHKE, Wendy (Ed.). The Archaeology of the Olympics: The Olympics and Other Festivals in Antiquity. 1a ed, Madison, WI: The Univ. of Wisconsin Press, 1988c, p. 13-25.

. Comments on "Archaeology into the 1990's". Norwegian Archaeological Review, v. 22, n. 1, p. 33-41, 1989a.

. Models of Change in Language and Archaeology. Transactions of the Philological Society, v. 87, n. 2, p. 103-155, 1989 b.

. Speculations on Linguistic Diversity. Paper presented to the first plenary meeting of Academia Europea, London, June 1989, 1989c.

. The Prehistory of Language: New Light upon Indo-European Origins. Scientific American, v. 261, n. 4, p. 82-90, 1989d.

- Before Babel: Speculations on the Origins of Linguistic Diversity. Cambridge Archaeological Journal, v. 1, n. 1, p. 3-23, 1991a.

.; BAHN, Paul. Archaeology: Theories, Methods and Practice. 1a ed, London: Thames \& Hudson, 1991b.

. The Cycladic Spirit: Masterpieces from the Nicholas P. Goulandris Collection. 1a ed, London: Thames \& Hudson, 1991c.

. Archaeology, Genetics and Linguistic Diversity. Man, v. 27, n. 3, p. 445-478, 1992a.

. The Identity and Future of Archaeological Science. In: POLLARD, Alan Mark (Ed.), New Developments in Archaeological Science: a Joint Symposium of the Royal Society and the British Academy, February 1991. 1a ed, Oxford: Oxford University Press, 1992b, p. 285294

. World Languages and Human Dispersal: a Minimalist View. In: HALL, John; JARVIE, Ian (Eds.). Transition to Modernity: Essays on Power, Wealth and Belief. $1^{\text {a }}$ ed, Cambridge, UK: Cambridge University Press, 1992c.

. The Roots of Ethnicity: Archaeology, Genetics and the Origins of Europe. 1a ed, Roma: 
Unione Internazionale degli Istituti di Archeologia, Storia e Storia dell'Arte in Roma, Conferenza, 8 gennaio 1993, Roma, 1993a.

.; BRADLEY, Richard. An interview with Colin Renfrew. Current Anthropology, v. 34, n. 1, p. 71-82, 1993b.

. Collectors are the Real Looters. Archaeology, v. 43, n. 3, p. 16-17, 1993c.

. Cognitive Archaeology: Some Thoughts on the Archaeology of Thought. Cambridge Archaeological Journal, v. 3, n. 2, p. 248-250, 1993d.

.; ZUBROW, Ezra (Eds.). The Ancient Mind: Elements of Cognitive Archaeology. 1a ed, Cambridge, UK: Cambridge University Press, 1994a.

. Towards a Cognitive Archaeology. In:

.; ZUBROW, Ezra (Eds.). The Ancient

Mind: Elements of Cognitive Archaeology. 1a ed, Cambridge, UK: Cambridge University Press, 1994b, p. 3-12

. The Archaeology of Religion. In: ; ZUBROW, Ezra (Eds.). The Ancient Mind: Elements of Cognitive Archaeology. 1a ed, Cambridge, UK: Cambridge University Press, 1994c, p. 3-12, p. 47-54.

. World Linguistic Diversity. Scientific American, v. 270, n. 1, p. 104-110, 1994d.

. The Archaeology of Identity. In: PETERSON, Grethe (Ed.). The Tanner Lectures on Human Values: Volume 15. 1a ed, Salt Lake City: University of Utah Press, p. 283-348, 1994e.

. Three Cambridge Prehistorians. In: MASON, Richard (Ed.). Cambridge Minds. 1a ed, Cambridge, 1994f, p. 58-71

. The Identity of Europe in Prehistoric Archaeology. Journal of European Archaeology, v. 2, n. 2, p. 153-174, 1994g.

.; BARBUJANI, Guido; PILASTRO, Andrea; DE DOMENICO, Silvia. Genetic Variation in North Africa and Eurasia: Neolithic Demic Diffusion vs. Paleolithic Colonisation. American Journal of Physical Anthropology, v. 95, n. 2, p. 137-154, 1994 h.

. Concluding Remarks: Childe and the Study of Cultural Process. In: HARRIS, David (Ed.). The Archaeology of V. Gordon Childe: Contemporary Perspectives. 1a ed, London: UCL Press, 1994i, p. 121-133.

- Language Families as Evidence of Human Dispersals. In: S. BRENNER, K. HANIHARA (Eds.), The Origins and Past of Modern Humans as Viewed from DNA: Proceedings of the Workshop on the Origin and Past of Homo Sapiens Sapiens as Viewed from DNA - Theoretical Approach. 1a ed, Singapore: World Scientific Publishing, 1995a, p. 285-306.

. Raiders of the Lost Past. Journal of Financial Crime, v. 3, n. 1, p. 7-9, 1995b.

. Foreword. In: N. SPENCER (Ed.). Time, Tradition and Society in Greek Archaeology: Bridging the 'Great Divide'. 1a ed, Abingdon: Routledge, p. xvi-xviii, 1995c.

. Introduction. In: TUBB, Kathryn (Ed.). Antiquities: Trade or Betrayed: Legal, Ethic and Conservation Issues. London: Archetype Books, p. xvii-xxi, 1995d.

. Language Families and the Spread of Farming. In: HARRIS, David (Ed.). The Origins and Spread of Agriculture and Pastoralism in Eurasia. London: UCL Press, 1996, p. 70-92. 


\section{BIBLIOGRAFIA GERAL ${ }^{33}$}

ÅBERG Nils. Bronzezeitliche und Früheisenzeitliche Chronologie, IV: Grichenland. 1a ed, Stockholm: Verlag der Akademie, 1933.

ADAMS, Robert McCormick. Anthropological Perspectives on Ancient Trade. Current Anthropology, v. 15, n. 3, p. 239-249, 1974.

AMMERMAN Albert; CAVALLI-SFORZA, Luigi Luca. A Population Model for the Diffusion of Early Farming in Europe. In: RENFREW, Andrew Colin (Ed.). The Explanation of Culture Change: Models in Prehistory. 1a ed, London: Duckworth, 1973, p. 343-357.

.; CAVALLI-SFORZA, Luigi Luca. The Wave of Advance Model for the Spread of Agriculture in Europe. In: RENFREW, Andrew Colin; COOKE, Kenneth (Eds.). Transformations: Mathematical Approaches to Culture Change. 1a ed, New York: Academic Press, 1979b, p. 275-293.

AMPOLO Carmine. Storia antica e antropologia: un rapporto difficile? Dialoghi di Archeologia, v. 4, n. 1, p. 127-131, 1986.

BARBER, R.L.N.; MACGILLIVRAY, Joseph Alexander. The Early Cycladic Period: Matters of Definition and Terminology. American Journal of Archaeology, v. 84, n. 2, p. 141-157, 1980.

BARKER Graeme. Review of 'Archaeology and Language'. Current Anthropology, v. 29, n. 3, p. 448449, 1988.

BATEMAN Richard; GODDARD, Ives; O'GRADY, Richard; FUNK, Vicki Ann; MOOI, Rich; KRESS, Walter John; CANNELL, Peter. Speaking of Forked Tongues: the Feasibility of Reconciling Human Phylogeny and the History of Language. Current Anthropology, v. 31, n. 1, p. 1-24, 1990.

BIETTI SESITIERI Anna. Organizzazione sociale e modelli matematici: I'archeologia di Colin Renfrew. Dialoghi di Archeologia, v. 3, n. 2, p. 109-115, 1985.

BINFORD Lewis Roberts. An Archaeological Perspective. 1a ed, New York: Seminar Press, 1972.

. (Ed.). For Theory Building in Archaeology: Essays on Faunal Remains, Aquatic Resources, Spatial Analysis, and Systemic Modeling. 1a ed, New York: Academic Press, 1977.

. Meaning, Inference and the Material Record. In: RENFREW, Andrew Colin; SHENNAN, Stephen (Eds.). Ranking, Resource and Exchange: Aspect of the Archaeology of Early European Society. 1a ed, Cambridge, UK: Cambridge University Press, 1982, p. 160-163.

.; BINFORD Sally. A Preliminary Analysis of Functional Variability in the Mousterian of the Levallois Facies. American Anthropologist, v. 68, n. 2, p. 238-295, 1966.

.; BINFORD Sally (Eds.). New Perspectives in Archaeology. 1a ed, Chicago: Aldine Publishing Company, 1968.

BLEGEN, Carl William. The Coming of the Greeks: II. The geographical distribution of prehistoric remains in Greece. American Journal of Archaeology, v. 32, n. 2, p. 146-154, 1928.

BROODBRANK Cyprian. The Spirit is Willing. Antiquity, v. 61, n. 251, p. 542-546, 1992.

33 As referências às traduções existentes em italiano foram eliminadas (N. T.). 
CAVALLI-SFORZA Luigi Luca. Chi siamo? La storia della diversità umana. 1aㅡ ed, Milano: Mondadori, 1993

CAZZELLA Alberto. L'archeologia dopo la New Archaeology: il rapporto con l'etno-antropologia. Dialoghi di archeologia, v. 3. N. 1, p. 11-24, 1985.

CHERRY John. Evolution, Revolution and the Origins of Complex Society in Minoan Crete. In: KRZYSZKOWSKA, Olga; NIXON, Lucia (Eds.). Minoan Society: Proceedings of the Cambridge Colloquium 1981. Bristol: Bristol Classical Press, 1983, p. 33-41.

CHILDE Vere Gordon. The Dawn of European Civilization. 1a ed, London: Kegan Paul, Trench, Turner \& Co., 1925.

. The Aryans: a Study of Indo-European Origins. 1a ed, London: Kegan Paul, Trench, Turner \& Co., 1926.

. The Danube in Prehistory. 1a ed, Oxford: Clarendon Press, 1929.

. The Orient and Europe: Presidential Address to Section H (Anthropology). British Association for the Advancement of Science, Report of the Annual Meeting, 1938, p. 181-196, 1938.

. Prehistoric Migrations in Europe. 1a ed, London: Kegan Paul, Trench, Turner \& Co., 1950.

. Piecing Together the Past. 1a ed, London: Kegan Paul, Trench, Turner \& Co., 1956.

. The Prehistory of European Society. 1a ed, London: Peguin Books, 1958.

CLARK, John Grahame Douglas. Prehistoric Europe: the Economic Basis. 1a ed, London: Methuen, 1952.

CLARKE, David Leonard. Analytical Archaeology. 1a ed, London: Methuen, 1968.

. (Ed.). Models in Archaeology, 1aㅡ ed, London: Methuen, 1972.

COLEMAN John Evander. Chronological and Cultural Divisions of the Early Cycladic Period: a Critical Approach. In: DAVIES, Jack; CHERRY, John (Eds.). Papers in Cycladic Prehistory. 1a ed, Los Angeles: UCLA Institute of Archaeology, 1979a, p. 48-50.

. Remarks on 'Terminology and Beyond'. In: DAVIES, Jack; CHERRY, John (Eds.). Papers in Cycladic Prehistory. 1a ed, Los Angeles: UCLA Institute of Archaeology, 1979b, p. 64-65.

COURBIN Paul. Qu'est-ce que l'archéologie ? Essai sur de la nature de la recherche archéologique. 1ạ ed, Paris: Payot, 1982.

CUOMO DI CAPRIO, Ninina. Ancora in tema di New Archaeology in Italia. Sibrium, v. 18, 3-15, 1986a. . Onde di propagazione della New Archaeology in Italia. Rivista di Archeologia, v. 10, p. 59-71, 1986b.

DYSON Stephen. A Classical Archaeologist's Response to New Archaeology. Bulletin of the American Schools of Oriental Research, v. 242, p. 7-13, 1981.

. From New to New Age Archaeology: Archaeological Theory and Classical Archaeology. American Journal of Archaeology, v. 97, n. 2, p. 195-206, 1993. 
FINLEY, Moses Isaac. Early Greece: the Bronze and Archaic Ages. 1a ed, London: Chatto \& Windus, 1970.

. Ancient History: Evidence and Modes. 1a ed, London: Chatto \& Windus, 1985.

FLEMING Andrew. An Embarrassment of Professor? Antiquity, v. 70, n. 267, p. 15-17, 1996.

GIMBUTAS Marija. Review of 'Archaeology and Language'. Current Anthropology, v. 29, n. 3, p. 453456, 1988.

. The Language of the Goddess: Unearthing the Hidden Symbols of Western Civilization. 1a ed, New York: Harper \& Row, 1989.

GREEN, Sally. Prehistorian: a Biography of V. Gordon Childe. 1a ed, Bradford-on-Avon: Moonraker Publications, 1981.

GREENBERG Joseph (Ed.). Universals of Language: Report of a Conference Held at Dobbs Ferry, New York, April 13-15, 1961. 2a ed, Cambridge, MA: MIT Press, 1966. . Language in the Americas. 1a ed, Stanford: Standford University Press, 1987.

GREPPI OLIVETTI, Alessandra. La nuova archeologia americana. Aspetti epistemologici. Quaderni di Filosofia dell'Università di Parma, v. 4, n. 22, 1982.

GUIDI Alessandro. Storia della paletnologia. 1ae ed, Bari: Editori Laterza, 1988.

HARRIS, David (Ed.). The Archaeology of V. Gordon Childe: Contemporary Perspectives. 1a ed, London: UCL Press, 1994.

HOCK, Henrich; JOSEPH Brian. Language History, Language Change and Language Relationship: an Introduction to Historical and Comparative Linguistics. 1a ed, Berlin: Mouton de Gruyter, 1996.

HODDER, lan. Comments on "Archaeology into the 1990's". Norwegian Archaeological Review, v. 22, n. 1, p. 15-21, 1989.

. On Cognitive Archaeology. Cambridge Archaeological Journal, v. 3, n. 2, p. 253-257, 1993.

JONES, Siân. The Archaeology of Ethnicity. 1a ed, London: Routledge, 1997.

KLEJN, Leo. A Panorama of Theoretical Archaeology. Current Anthropology, v. 18, n. 1, p. 1-42, 1977.

LAMBERG-KARLOVSKJ, Clifford Charles. Introduction. In: . (Ed.). Archaeological Thought in America. 1a ed, Cambridge, UK: Cambridge University Press, 1989, p. 1-16.

LEACH, Edmund. Concluding Address. In: RENFREW, Andrew Colin (Ed.). The Explanation of Culture Change: Models in Prehistory. 1a ed, London: Duckworth, 1973, p. 761-771.

LEPSCHY, Giulio Ciro. La linguistica del Novecento. 1ạ ed, Bologna: II Mulino, 1992.

MARUYAMA, Magoroh. The Second Cybernetics: Deviation-Amplifying Mutual Causal Processes. American Scientist, v. 51, n. 2, p. 164-179, 1963.

MORRIS Ian (Ed.). Classical Greece: Ancient History and Modern Archaeologies. 1a ed, Cambridge, UK: Cambridge University Press, 1994. 
RUHLEN, Merritt. A Guide to the World's Languages. 1a ed, Stanford: Stanford University Press, 1987.

SERVICE, Elman Rogers. Primitive Social Organisation: An Evolutionary Perspective. 2a ed, New York: Random House, 1966.

SHANKS, Michael; TILLEY, Cristopher. Re-Constructing Archaeology: Theory and Practice. 1a ed, Cambridge, UK: Cambridge University Press, 1987a.

.; TILLEY, Cristopher. Social Theory and Archaeology. 1a ed, Cambridge: Polity Press, 1987b.

.; TILLEY, Cristopher. Archaeology into the 1990's. Norwegian Archaeological Review, v. 22, n. 1, p. 1-12, 1989.

SHENNAN, Stephen (Ed.). Archaeological Approaches to Cultural Identity. 1a ed, London: Routledge, 1989.

SHERRATT, Andrew. Review of 'Archaeology and Language'. Current Anthropology, n. 29, n. 3, p. 458463, 1988.

. V. Gordon Childe: Archaeology and Intellectual History. Past and Present, v. 125, p. 151-185, 1989.

. Childeish Question. Antiquity, v. 70, n. 267, p. 18-19, 1996.

. Economy and Society in Prehistoric Europe: Changing Perspectives. 1a ed, Edinburgh: Edinburgh University Press, 1988.

SNODGRASS Anthony McElrea. The New Archaeology and the Classical Archaeology. American Journal of Archaeology, v. 89, n. 1, p. 31-37, 1985.

. An Archaeology of Greece: the Present State and Future Scope of a Discipline, 1a ed, Berkeley: University of California Press, 1987.

TRIGGER, Bruce Graham. Time and Traditions: Essays in Archaeological Interpretations. 1a ed, Edinburgh: Edinburgh University Press, 1978.

. Gordon Childe: Revolutions in Archaeology. 1a ed, London: Thames \& Hudson, 1980.

. Comments on "Archaeology into the 1990's". Norwegian Archaeological Review, v. 22, n. 1, p. 28-31, 1989a.

. A History of Archaeological Thought. 1a ed, Cambridge, UK: Cambridge University Press, 1989b.

. Childe's Relevance to the 1990s. In: HARRIS, David (Ed.). The Archaeology of V. Gordon

Childe: Contemporary Perspectives. 1a ed, London: UCL Press, 1994, p. 9-34.

VILLAR Francisco. Los indoeuropeos y los orígenes de Europa. Lenguaje e historia. 1a ed, Madrid: Editorial Gredos, 1991.

WHITE Leslie. The Evolution of Culture: the Development of Civilization to the Fall of Rome. 1a ed, New York: McGraw-Hill, 1959. 


\section{TRADUÇÕES EM PORTUGUÊS DE ITENS DA BIBLIOGRAFIA (N. T.)}

CAVALLI-SFORZA, Luigi Luca. Quem somos? História da diversidade humana. 1a ed, São Paulo: Ed. UNESP, 2002 [1993].

CHILDE, Vere Gordon. Para uma recuperação do passado. 1ạ ed, São Paulo: Difel, 1956 [1956]. . A aurora da civilização europeia. 1a ed, Portugal: Portugália, 1961 [1925].

FINLEY, Moses Isaac. Grécia primitiva: Idade do Bronze e Idade Arcaica. 1ạ ed, São Paulo: Martins Fontes, 1990 [1970]. . História antiga: testemunhos e modelos. 1a ed, São Paulo Martins Fontes, 1994 [1985].

RENFREW, Andrew Colin. Varna e o surgimento da riqueza na Europa pré-histórica. In: APPADURAI, Arjun (Ed.). A vida social das coisas: as mercadorias sob uma perspectiva cultural. 1a ed, Niterói: Ed. UFF, 2008 [1986].

SERVICE, Elman Rogers. Organização social primitiva. 1a ed, Porto: Despertar, 1970 [1966].

TRIGGER, Bruce Graham. História do pensamento arqueológico. 1a ed, São Paulo: Odysseus, 2004 [1989b]. 